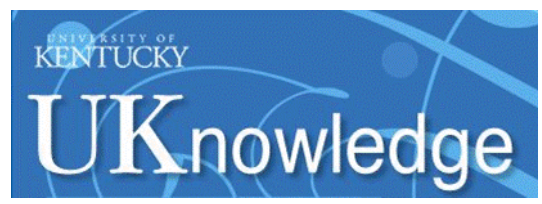

University of Kentucky

UKnowledge

\title{
Breast Disorders in Children and Adolescents
}

Donald E. Greydanus

Michigan State University

Hatim A. Omar

University of Kentucky, hatim.omar@uky.edu

Lyubov A. Matytsina

Donetsk Medical University, Russia

Artemis Tsitsika

University of Athens, Greece

Follow this and additional works at: https://uknowledge.uky.edu/pediatrics_facpub

Part of the Pediatrics Commons, and the Physiology Commons

Right click to open a feedback form in a new tab to let us know how this document benefits you.

\section{Repository Citation}

Greydanus, Donald E.; Omar, Hatim A.; Matytsina, Lyubov A.; and Tsitsika, Artemis, "Breast Disorders in Children and Adolescents" (2010). Pediatrics Faculty Publications. 262.

https://uknowledge.uky.edu/pediatrics_facpub/262

This Book Chapter is brought to you for free and open access by the Pediatrics at UKnowledge. It has been accepted for inclusion in Pediatrics Faculty Publications by an authorized administrator of UKnowledge. For more information, please contact UKnowledge@lsv.uky.edu. 


\section{Breast Disorders in Children and Adolescents}

\section{Notes/Citation Information}

Published in Pediatric and Adolescent Sexuality and Gynecology: Principles for the Primary Care Clinician. Hatim A. Omar, Donald E. Greydanus, Artemis K. Tsitsika, Dilip R. Patel, \& Joav Merrick, (Eds.). p. 245-316.

(c) 2010 Nova Science Publishers, Inc.

The copyright holder has granted the permission for posting the book chapter here. 
In: Pediatric and Adolescent Sexuality...

ISBN: 978-1-60876-735-9

Ed: H. A. Omar et al.

(C) 2010 Nova Science Publishers, Inc.

\section{Chapter 6}

\section{BREAST DISORDERS IN CHILDREN AND ADOLESCENTS}

\section{Donald E Greydanus*, MD, Hatim A Omar, MD, Lyubov Matytsin, MD, PhD and Artemis Tsitsika, MD, PhD}

Pediatrics and Human Development, Michigan State University College of Human Medicine, Michigan Stale University/Kalamazoo Center for Medical Studies, Kalamazoo, Michigan, United States of America, Adolescent Medicine and Young Parent Programs, Kentucky Clinic, University of Kentucky, Lexington, Kentucky, United States of America, Donetsk Medical University, Ukraine, Russia, Adolescent Health Unit (AHU), Second Department of Pediatrics, University of Athens, P \& A Kyriakou Children's Hospital, Athens, Greece

Correspondence: Donald E Greydanus, MD, Professor, Pediatrics and Human Development, Michigan State University College of Human Medicine, Pediatrics Program Director, Michigan State University Kalamazoo Center for Medical Studies. 1000 Oakland Drive, Kalamazoo, Michigan 490081284 United States Email: Greydanus@kcms.msu.edu 
Concerns about problems of the breast are often noted in adolescents and their parents. This review discusses issues and disorders of the breast in children and adolescents, starting with basic principles of embryology and adolescent breast development. Concepts that are covered include congenital breast disorders, abnormal timing of breast development, breast asymmetry, underdeveloped breasts, breast atrophy, tuberous breasts, mammary hyperplasia, fibroadenoma, giant fibroadenoma, cystosarcoma phyllodes, intraductal breast papilloma, adenocarcinoma, mastitis, traumatic breast disorders, benign breast disease, fibrocystic change, mastalgia, gynocomastia, and galactorrhea. A number of figures are provided illustrating breast pathology. Clinicians caring for children and adolescents are encouraged to provide careful assessments of this important organ system.

\section{INTRODUCTION}

The breast is a modified sweat gland enveloped by superficial thoracic fascial layers and suspended from the chest wall by Cooper's ligaments (fibrous septae), extending from the pectoralis fascia to the dermis $(1,2)$. Breast concerns and disorders are an often ignored part of health care, sometimes neglected by the clinician, and typically worried about by the child or adolescent. Parents may be anxious about perceived breast problems in their child while the adolescent may present with unexpressed concerns about this body system. Body image and self esteem issues in girls may be strongly associated with breast appearance and breast development during the adolescent years. Breasts (mammary glands) are estrogen-dependent organs that indicate sex development, functional activity of ovary, and development of reproductive function. Diagnosis and treatment of breast disorders are important tasks for clinicians who care for children and adolescents (3-5). Examination of the breasts may occur as part of a comprehensive physical examination or because anxiety is raised about a possible problem. This review presents common concerns and problems of the breast that may arise in children and adolescents (6-8). 


\section{EMBRYOLOGY}

During the 4th to the 6th fetal week, epidermal cells migrate into underlying mesenchyme, resulting in the development of primitive mammary ridges or milk lines (9). Ectodermal thickening occurs from the axilla to the groin. Atrophy of the upper and lower parts of these ridges usually occurs around the 10th fetal week, allowing the middle or pectoral ridges to eventually become normal breast tissue. Lactiferous duct and mammary glands later develop from these ridges, while the surrounding mesenchyme becomes fibrous and adipose tissue within the breast. Solid cords, usually 15 to 20 in number, result from secondary buds in the breast tissue; these cords later become milk ducts and lobes of the breasts. The areola develops in the 5th month of fetal life and the nipple is normally seen shortly after birth.

\section{NORMAL ADOLESCENT BREAST DEVELOPMENT}

Childhood breasts are composed of ducts that are lined with epithelium and surrounded by connective tissue; the child's breast tissue usually is dormant until puberty ensues (9). As puberty develops, female breasts change due to the increase of the hormones estrogen, progesterone, and eventually, prolactin. However, during premature (isolated) thelarche/ premature breast development, the level of estrogen is not increased. Some researchers believe that testosterone could have specific influence for breast development, but this opinion is still controversial (10). For example, absence of suppressive effects of testosterone for breast development in girls with a low estrogen level who are not sensitive to androgen, could lead to normal size breasts, as in the case of androgen insensitivity syndrome (testicular feminization syndrome). Perhaps breasts develop under increasing estradiol secretion by testicles and peripheral aromatization of testosterone (10). Other hormones needed for normal breast growth include thyroxine, insulin, growth hormone, and adrenal corticosteroids. Deficiency in one or more of these hormones can result in defects of the breast organ. 
At first in early puberty, there is an increase in adipose tissue along with initial growth of ductal and stromal tissue because of the effects of estrogen; increase in pigmentation and size of the areola are also due to estrogen effects. The increase in progesterone leads to alveolar budding, lobular growth, and secretory growth of lobules and alveoli; however, true alveoli only appear during pregnancy (11).

The growth of female breasts is divided into five stages, classically called Tanner Stages or Sexually Maturity Stages (SMR) (see figure 1) (12). The SMR stages of Tanner from 1962 were based on classic work of Reynolds and Wines in 1948 that was itself based on earlier work of Stratz in $1909(1,2)$. There is no breast development in stage 1 , the classic breast bud is stage 2 , the small breast appearance is stage 3 , the doublecontoured appearance is stage 4 (due to the areola/nipple complex forming one mound on top of the breast tissue mound), and the single contour appearance with the nipple forming a little round edge on the top, is stage 5 (fully mature breast). Some adolescent females may not develop a stage 5 breast and may have the stage 4 appearance throughout adulthood. Persistence of stage 4 in adult life does not pose problems in general, though special advice and preparation is needed for lactation.

A number of clinical correlations are noted with the SMR stages (see table 1). Alveolar cells change into secretory cells, with full maturation developing later with the production of prolactin inducing alveoli that are lined with mild secreting cells. Edema fluid can increase in size by $50 \%$ during the luteal phase of the cycle and these females could eventually develop symptoms of premenstrual tension (PMT)/premenstrual syndrome (PMS) that include breast tenderness and swelling.

The mature breast can increase two to three times in size due to pregnancy, from the second month of pregnancy, under the influence of estrogen and progesterone produced by the placenta, and also lactation. The breasts start to enlarge due to increased fat deposition and glandular proliferation with potential doubling of the breast blood flow. Breast anatomy is shown in figures $2-4(13,14)$. There are 15-20 lobes, consisting of 20-40 lobules which include 10-100 alveoli. The areola contains numerous Montgomery (sebaceous) glands (11). 


\section{Table 1. Clinical correlations with Tanner Stages ${ }^{\star}$}

\begin{tabular}{|c|c|}
\hline Clinical features & Tanner stage \\
\hline Hematocrit rise in males & III-V \\
\hline Alkaline phosphatase peak & II in female, III in male \\
\hline Rise in serum uric acid levels (male) & IIIIV \\
\hline $\begin{array}{l}\text { Mild regression of virginal hypertrophy } \\
\text { (of breast) }\end{array}$ & $\mathrm{V}$ \\
\hline $\begin{array}{l}\text { Different counseling about concern for } \\
\text { breast size }\end{array}$ & II or $\mathrm{V}$ \\
\hline Appearance of menarche Appearance & Late III or IV \\
\hline $\begin{array}{l}\text { of"normal" gynecomastia } \\
\text { (males) }\end{array}$ & II or III \\
\hline Use of contraceptives & IV \\
\hline Use of diaphragm & IV or $\mathrm{V}$ \\
\hline \multicolumn{2}{|l|}{ Neisseria gonorrhoeae infection } \\
\hline Vaginitis & I \\
\hline Cervictis & III+ \\
\hline Timing ofbreast reduction or rhinoplasty $=$ & $\mathrm{V}$ \\
\hline Short male with growth potential & II \\
\hline Short male with limited growth potential & IV \\
\hline Appearance of acne vulgaris & II or III \\
\hline $\begin{array}{l}\text { Decreased incidence of serous otitis } \\
\text { media }\end{array}$ & Post-II or III \\
\hline $\begin{array}{l}\text { Development oforthopedic disorders } \\
\text { (Osgood-Schlatter disease, slipped capital } \\
\text { femoral epiphysis, significant worsening } \\
\text { of scoliosis) }\end{array}$ & II-III (II-IV for scoliosis) \\
\hline Strong suspicion of organic disease & $\begin{array}{l}\text { Regression of stages or } \\
\text { unusual delay in stage } \\
\text { progression }\end{array}$ \\
\hline
\end{tabular}

*Used with permission from: Greyadanus DE, Parks D, Farrell E. Disorders of the breasts in children and adolescents. Pediatr Clin North Am 1989;36:601-38 
Figure 1. Tanner Stages or Sexually Maturity Rating Stages (SMR).

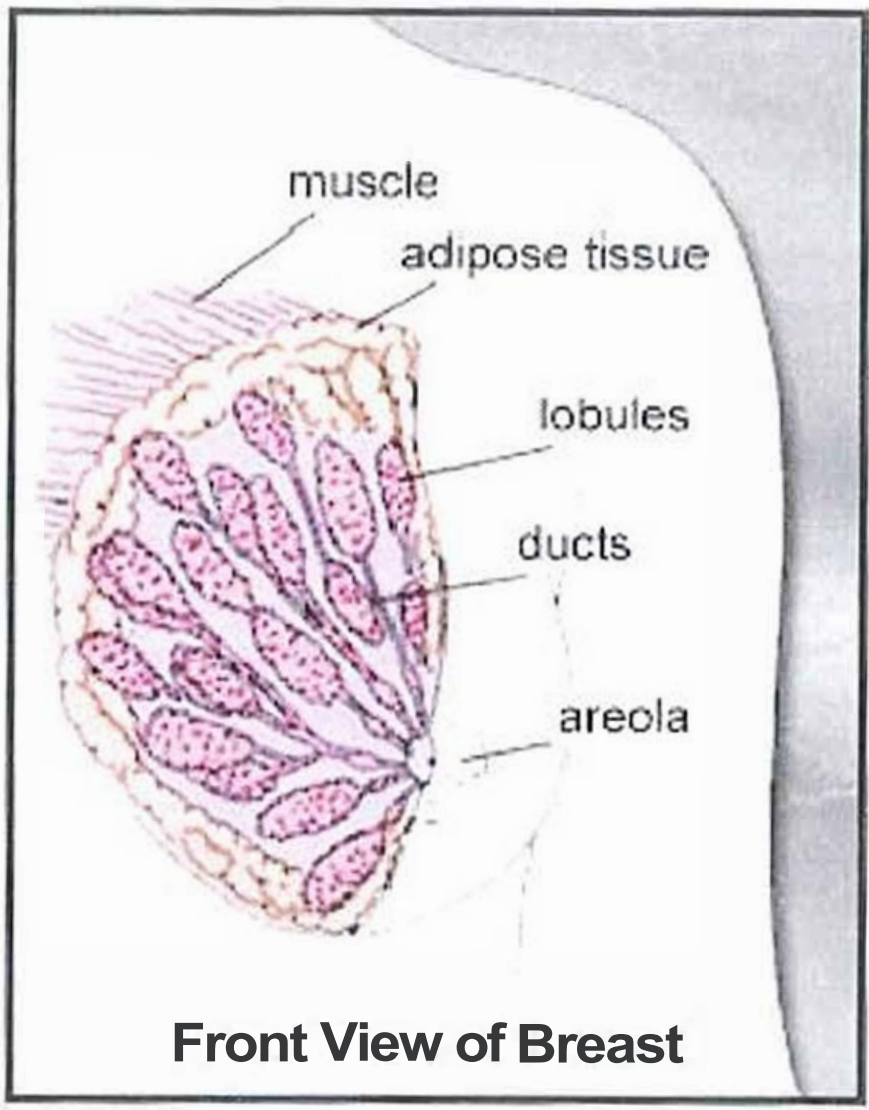

Figure 2. Breast Anatomy. 
Chest wall

\section{Pectoralis muscles}

Lobules

Nipple surface

Areola

\section{duct}

\section{Fatty tissue}

Skin

Figure 3. Breast Anatomy. 


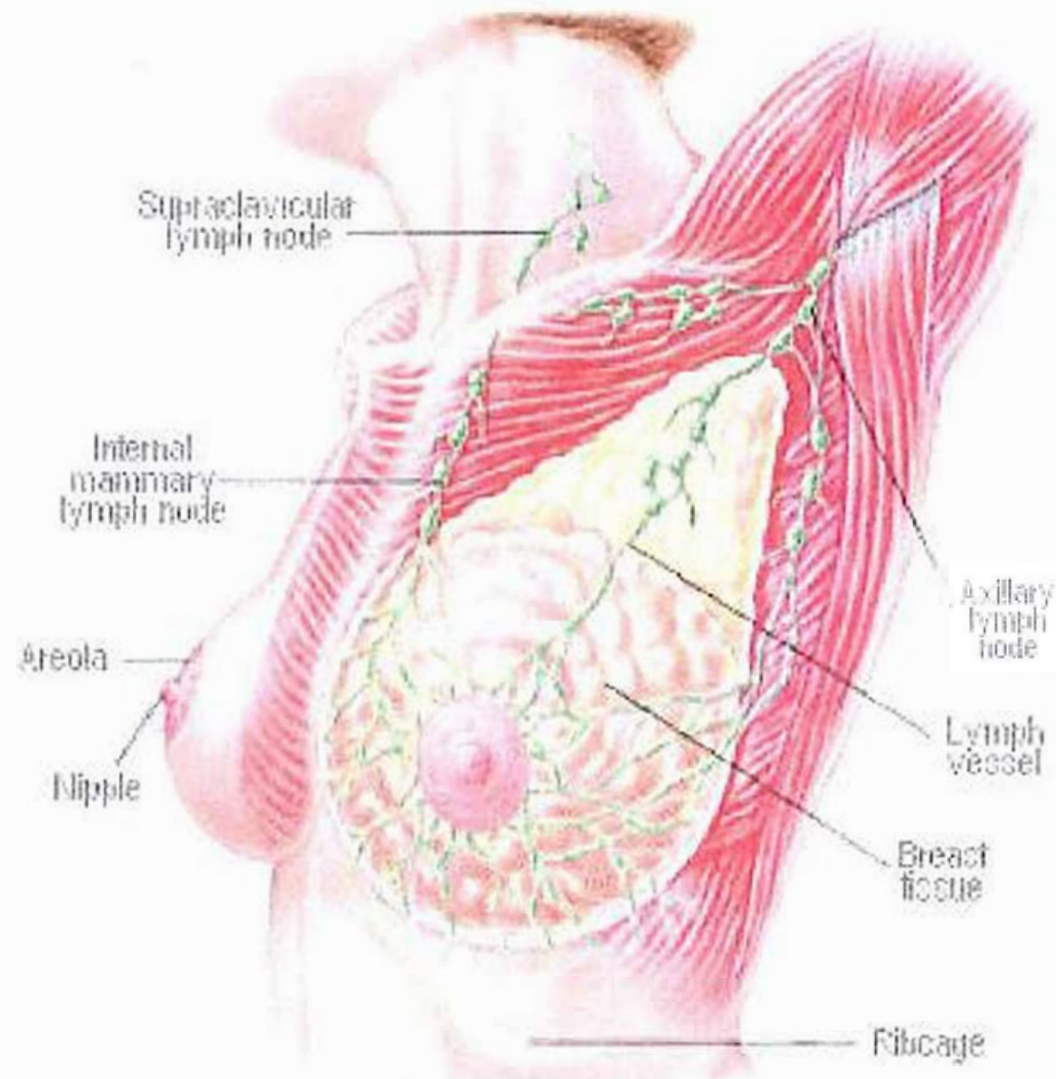

Figure 4. Breast Anatomy.

\section{BREAST EXAMINATION}

\section{Self-examination}

Many clinicians would not recommend routine self-breast examinations in adolescent females (except in those with a family or personal history of breast cancer), since breast malignancy is rare in this age group and it may produce increased psychological distress searching for such a rare condition; also, adolescents often do not exam themselves routinely for various reasons including limited knowledge of their bodies and busy life 
activities that block their attention for such a recommendation. Arguments for encouraging youth to start breast exams is that it prepares them for such self-examinations as adults and that it is an effective way to find breast pathology.

\section{Clinicians' examinations}

A number of methods for breast examination have been described and can be applied depending on the purpose of the examination $(4,14)$. The male clinician may perform a limited exam, because of his own anxiety, concern over the patient's reaction to a breast exam, or out of a belief that no pathology is present in an adolescent. The male clinician may feel more comfortable with a chaperone in the room during the breast examination, as typically occurring during a pelvic examination (4). It is important to assess if the patient has any concerns about her breastssuch as being too small, too large, asymmetrical, or other. The exam can be used to provide often needed education about this important part of her body and its implications for current and future sexuality.

The adolescent should be taught that there is considerable amount of normal variation of breast size, shape, and consistency. Nipple size may also be quite varied. Swelling or enlargement may be noted along the outer lateral breast tissue curve extending into the axilla; this "axillary tail ofSpence" is normal and can enlarge during puberty and pregnancy. There is also a normal variation in areolar hair, especially in some ethnic groups; however, this can be the first symptom of hyperandrogenemia and hirsutism $(15,16)$. Plucking these hairs can lead to ingrown hairs and infection. If these hairs are bothersome, they can be cut short. A normal finding is a variable amount of areolar gland discharge and this should not be confused with galactorrhea. Also, the areola contains Montgomery tubercles that may temporarily secrete a whitish discharge under the stimulation of puberty, pregnancy, or lactation; it is not a disorder, is transient, and the only treatment is simple reassurance of its normalcy.

A number of tests have been used to delineate breast pathology. Masses may be evaluated with fine-needle aspiration (FNA), core-needle biopsy $(\mathrm{CNB})$, or excisional biopsy $(4,17,18)$. A mammogram is usually not very helpful in adolescent females, because of the breast denseness 
(i.e., increased fibroglandular to fatty tissue ratio) and also if the breasts arc small (19). Ultrasonography is more effective at delineating masses within the immature breast $(4,18,20)$. Color Doppler ultrasonography may increase the specificity of the diagnosis; cysts are avascular, fibroadenomas are hypovascular, and abscesses show increased peripheral flow (21). Computerized tomography (CT) may be necessary to locate a lesion in the breast tissue versus chest wall or other structures. The combination of palpation, imaging, and biopsy (FNA or CNB) is called the "triple test" of breast lesion evaluation $(17,22)$.

\section{CONGENitAL ANOMALIES}

\section{Nipple anomalies}

A number of breast congenital anomalies can be seen, as noted in table 2 . Polythelia or extra nipples, is described in $1 \%$ to $2 \%$ of the general population, and may be associated with ocher anomalies, such as genitourinary or cardiovascular defects (see figures 5,6) $(9,14)$. These accessory nipples can be located anywhere along the milk lines, from the axilla to the groin (see figure 7); other sites have been noted as well, such as over the back or buttock (4). The nipple and areola of the accessory tissue is usually smaller than a normal nipple and may be mistaken for a mole, melanoma, or hemangioma (see figure 8). Excision of the extra nipple (s) is the typical management if the patient requests a cosmetic removal.

\section{Table 2. Congenital anomalies of the breast}

Polythelia
Athielia
lnverted nipples
Bifid nipple
Depressed nipple
Polymastia
Symmastia
Amastia
Poland syndrome




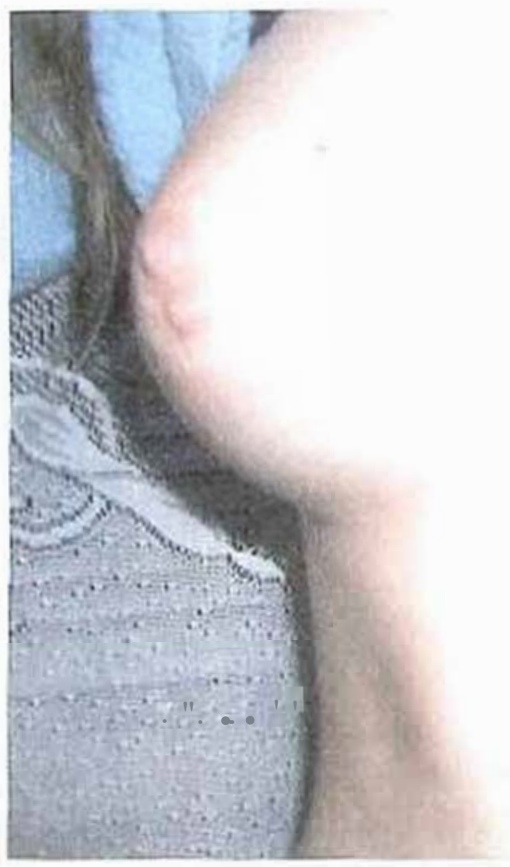

Figure 5. Congenital anomalies: two nipples (right breast) in a 14 year old girl. Mole is seen at the medial aspect ofright breast

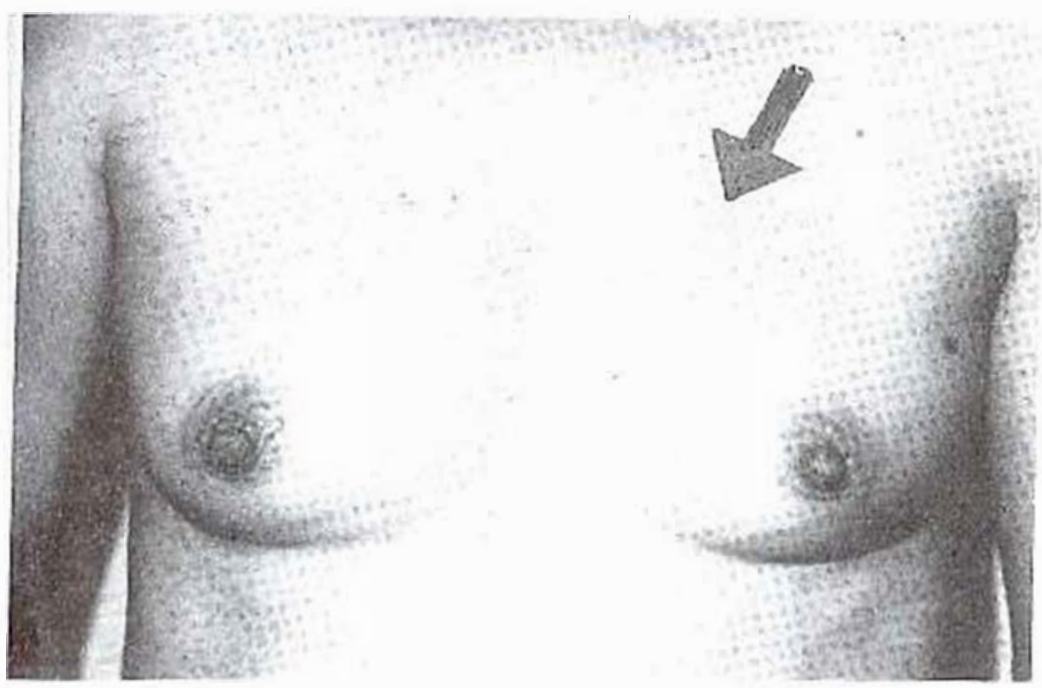

Figure 6. Accessory nipple or polythelia (arrow). 


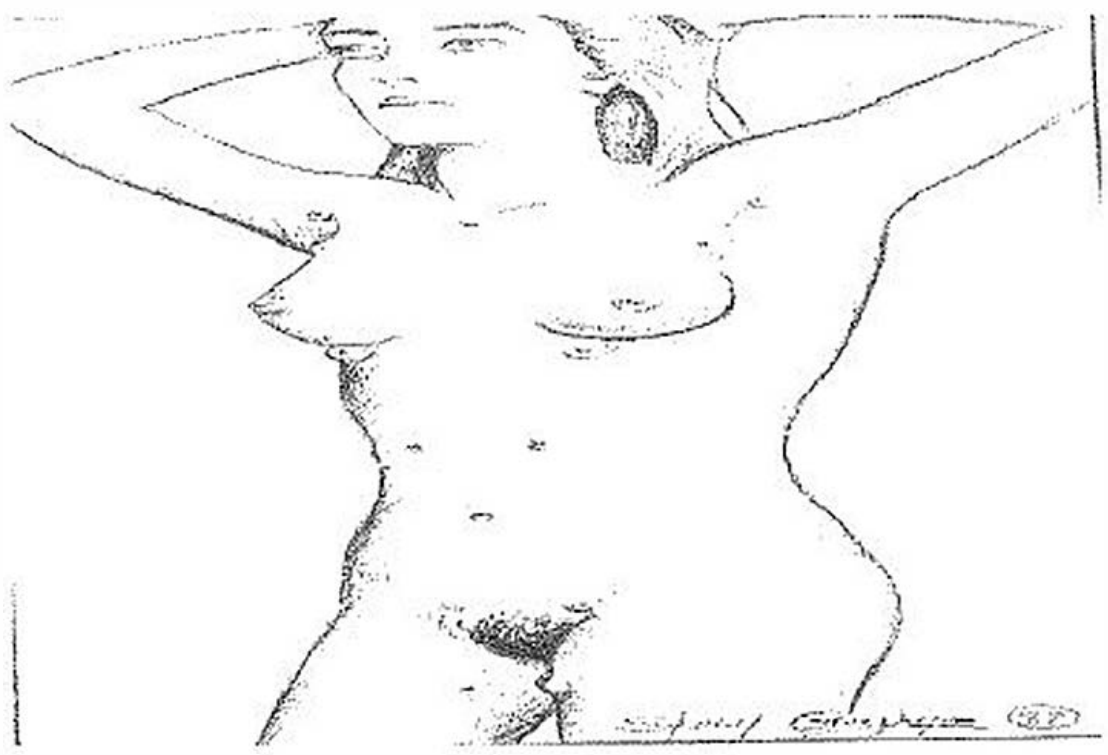

Figure 7. Embryonic milk tines.

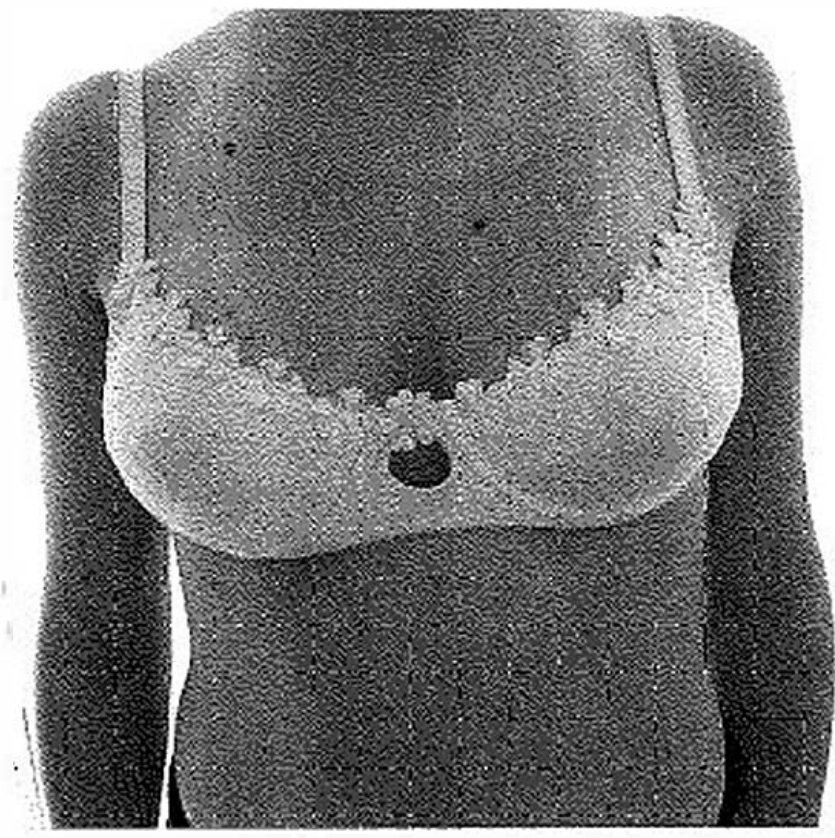

Figure 8. Hemangioma in the left breast in a 16 year old girl. 
An inverted nipple is one that does not project beyond the breast surface and is noted at birth; it is typically bilateral and usually reverts to normal in a few weeks. If persistent into the adolescent years, cosmetic and lactation concerns often arise. The infraareolar breast tissue can be compressed and may lead to nipple protrusion. Infection can develop in an inverted nipple unless hygiene is excellent at all times and can lead to chronic areolar abscesses with swelling, erythema, pain, and discharge of the involved nipple (s). Management includes local beat application, antibiotics, and surgery co divide the breast ducts and raise the nipple; however, breast feeding potential is then typically compromised. Acute onset of nipple inversion in adolescence or adulthood suggests such problems as duct ectasia or malignancy that commonly presents as unilateral nipple inversion.

Other nipple anomalies include a bifid nipple (see figure 9) and a depressed nipple; the latter involves lactiferous ducts that directly open into a depressed areolar center and if severe, breast feeding is prevented. Management is with surgical correction as with the inverted nipple. The absence of a nipple, athelia, is a very rare condition and may also be seen as a unilateral, bilateral, and/or familial condition; it may occur with exposure to exogenous androgen taken during pregnancy.

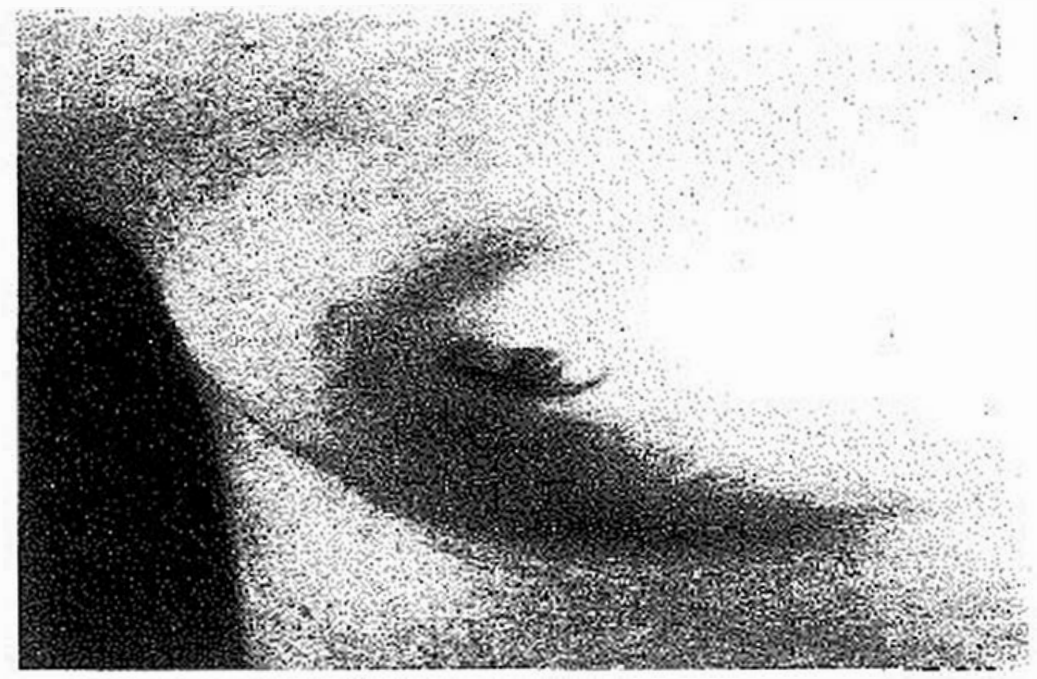

Figure. 9. Bifid nipple. A rare breast anomaly that is apartial duplication of the nipple. 


\section{Polymastia/Amastia}

Polymastia or supen1umerary breasts is noted less commonly than polythelia and like extra nipples (see figures 5,6), can be unilateral, bilateral, and/or familial. An extra breast (polymastia) or extra nipple (polythelia) occurs in approximately $1 \%$ of the population and may be an inherited condition (23). Supernumerary nipples are slightly more common in males than in females. The extrabreast tissue can be seen anywhere along the milk lines, but they are typically found below a normal breast, on the chest or upper abdomen. Various combinations of nipple, areola and glandular breast tissue can be seen, leading to confusion with other conditions, including hidradenitis suppurativa. The extra tissue may become readily apparent with puberty, pregnancy, and/or lactation. This accessory tissue is usually removed for cosmetic and/or diagnostic reasons, but other indications include an axillary location and the presence of lactation. There are rare case reports of a malignancy developing in supernumerary breast tissue (24). Another rare congenital anomaly of the breast is symmastia, with breast tissue webbing or confluence in the midline.

The absence of a breast (amastia) is rare and occurs because of complete mammary ridge involution, incluiling the pectoral ridge on the affected side. Amastia, like athelia, can be associated with chest wall anomalies as pectus excavatum or the Poland syndrome. The Poland syndrome (see figures I0,11) describes a condition with various combinations of anomalies, such as amastia, pectoralis muscle aplasia, rib defomuties, and upper limb defects (such as radial nerve aplasia and finger webbing) $(1,2,4,9,14,25)$. Management includes surgical correction of the chest wall deformities. Amastia can be acquired because of damage from a breast bud biopsy, irradiation to the breast area, or other injury to breast tissue. An abnormal breast appearance can also be seen with pectus excavatum (see figure 12). 


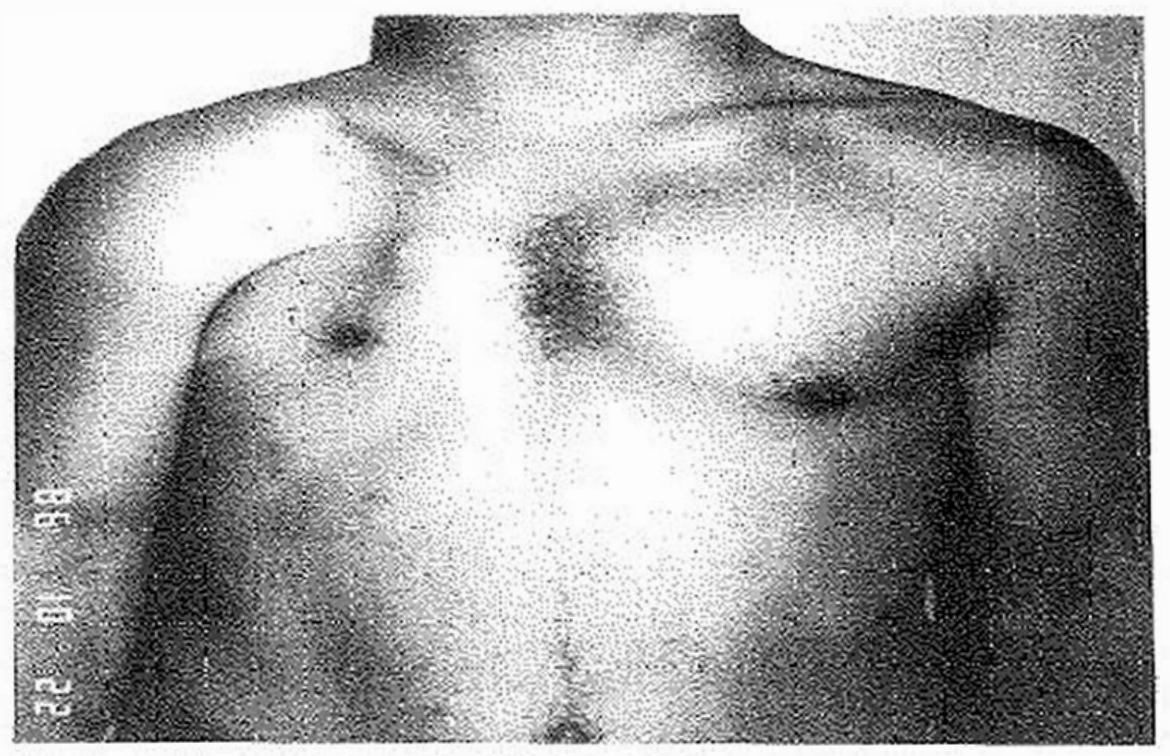

Figure 10. Poland Syndrome.

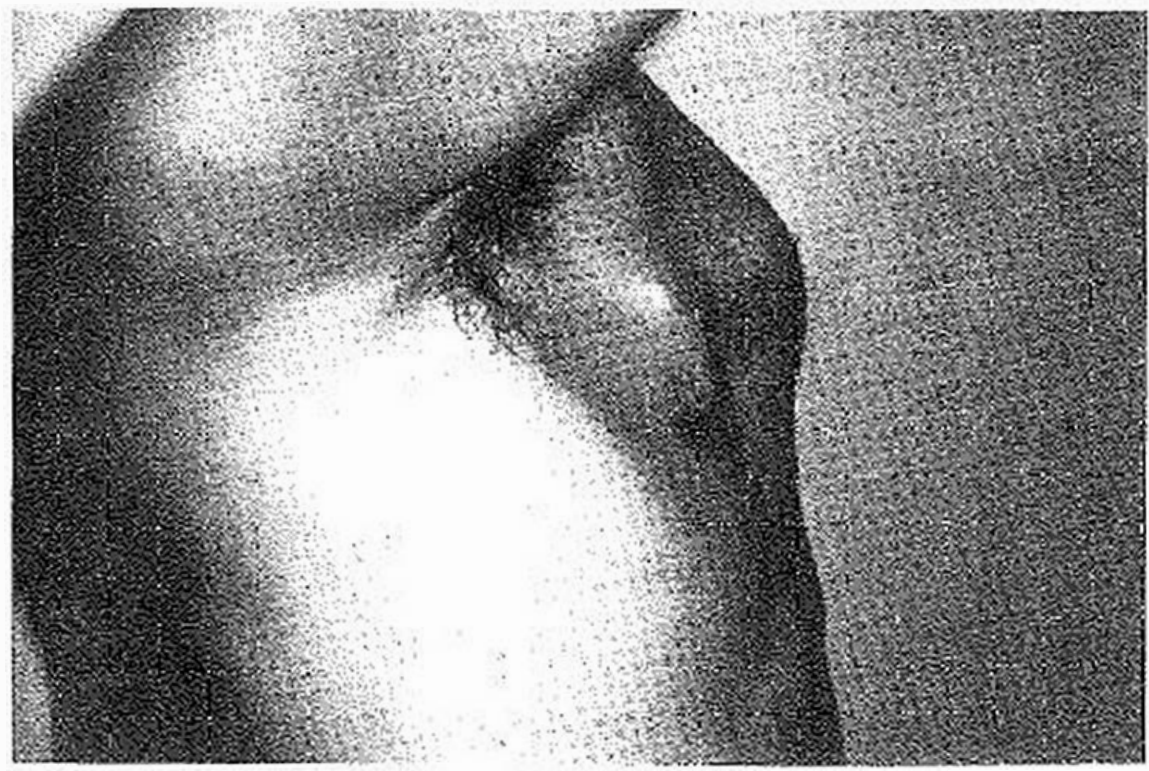

Figure 11. Poland Syndrome (same patient as figure 10, lateral view). 


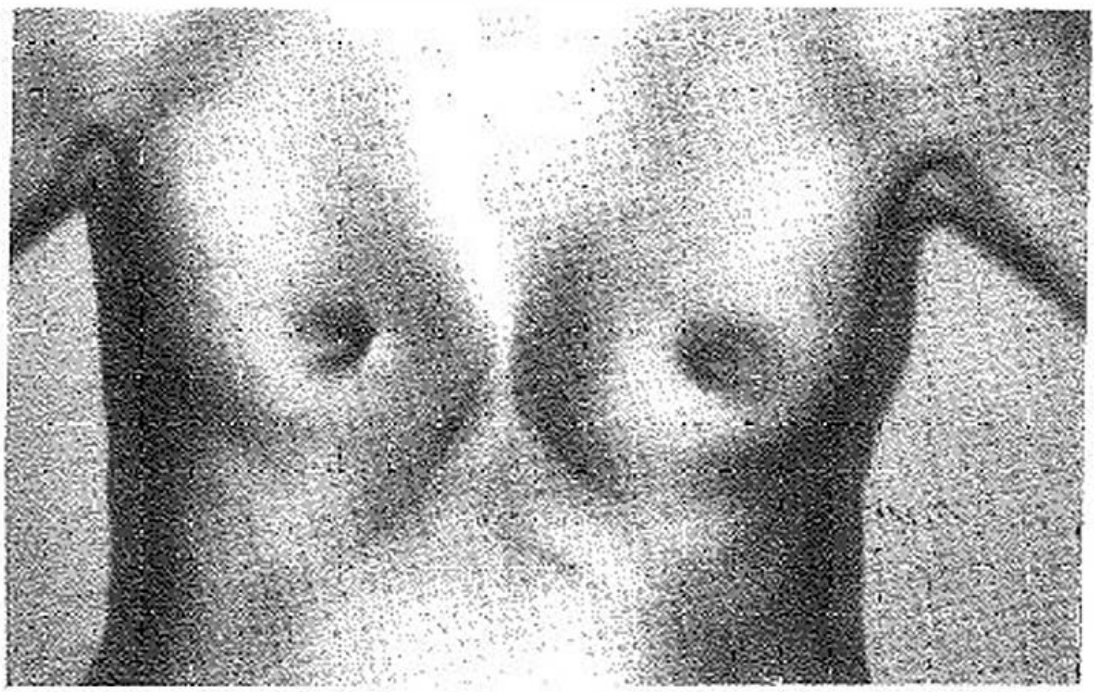

Figure 12. Pectus Excavatum. A classic chest wall deformity that can affect the breast appearance. Reconstructivc surgery may improve the cosmetic appearance.

\section{TIMING OF BREAST DEVELOPMENT}

Thelarche (onset of breast development) begins at an average age of 10 to $101 / 2$ years of age with a normal variation of 6-8 years at the earliest to 13 years at the latest, and it is the first sign of puberty in females in most cases (26-28). The exact timing of bow early breast development may arise before identifying it as premature remains debated by various experts. Some research suggests that thelarche may normally begin as early as age 6 years in African-Amelican children and 7 years in Caucasian children; approximately $48 \%$ of African-American females have thelarche between 8 and 9 years of age versus $1.5 \%$ of Caucasian females (29). Thus, the definition of precocious puberty and delayed puberty may vary from expert to expert. Once breast development begins, it usually takes 2 to 3 years for full breast development, and about two to three years ( $14-4$ years) for menarche (onset of menstrual periods) (26,28). Some females remain at SMR 3 until pregnancy and they can be reassured of the normalcy of these breasts in a world often obsessed with "full" breasts. 
The average age of menarche dropped in the United States from the 1800s to the mid-1990s for reasons usually linked to improved nutrition and health as well as increased weight (26). There is no clear evidence that age of menarche continued to decline from the mid-1900s to the present and it appears to have stabilized at age 13 in Northern Europe. In less developed countries and those with warm climates, it appears to be still dropping (26). Earlier puberty may lead to earlier sexual activity with resultant complications of high risk behaviors, such as pregnancy, date violence, school failure, and others.

Premature thelarche (see figure 13) is defined by the isolated appearance of breasts in the female child under age 6 to 8 years of age without other evidence of puberty (such as pubarche or menarche) $(4,30)$. It has a prevalence of $2 \%$ and typically, is noted between ages 1 and 3 years with normal laboratory studies (see table 3); sometimes, serum estradiol may be slightly increased. Table 4 lists potential causes of premature thelarche. A careful history is important to identify potential sources of exogenous estrogen exposure. Further evaluation reveals no estrogen effect on the vagina (i.e., vaginal cytology change), no further progression of breast tissue, and no other evidence of puberty (such as development of pubic hair, thickening of the vaginal mucosa, or accelerated bone growth). If no other signs of puberty are present, reassure the patient and family that this is a benign finding. Examine the child every 6-12 months; if other signs of puberty are evident, precocious puberty should be entertained as a diagnosis, In premature thelarche, the breast budding may persist until later puberty; if there is breast development beyond SMR 2, it typically regresses until later, usually normal puberty occurs.

\section{Table 3. Potential laboratory studies to evaluate premature thelarche}

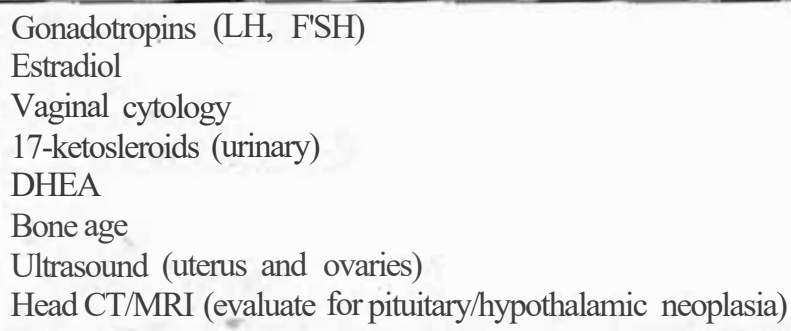




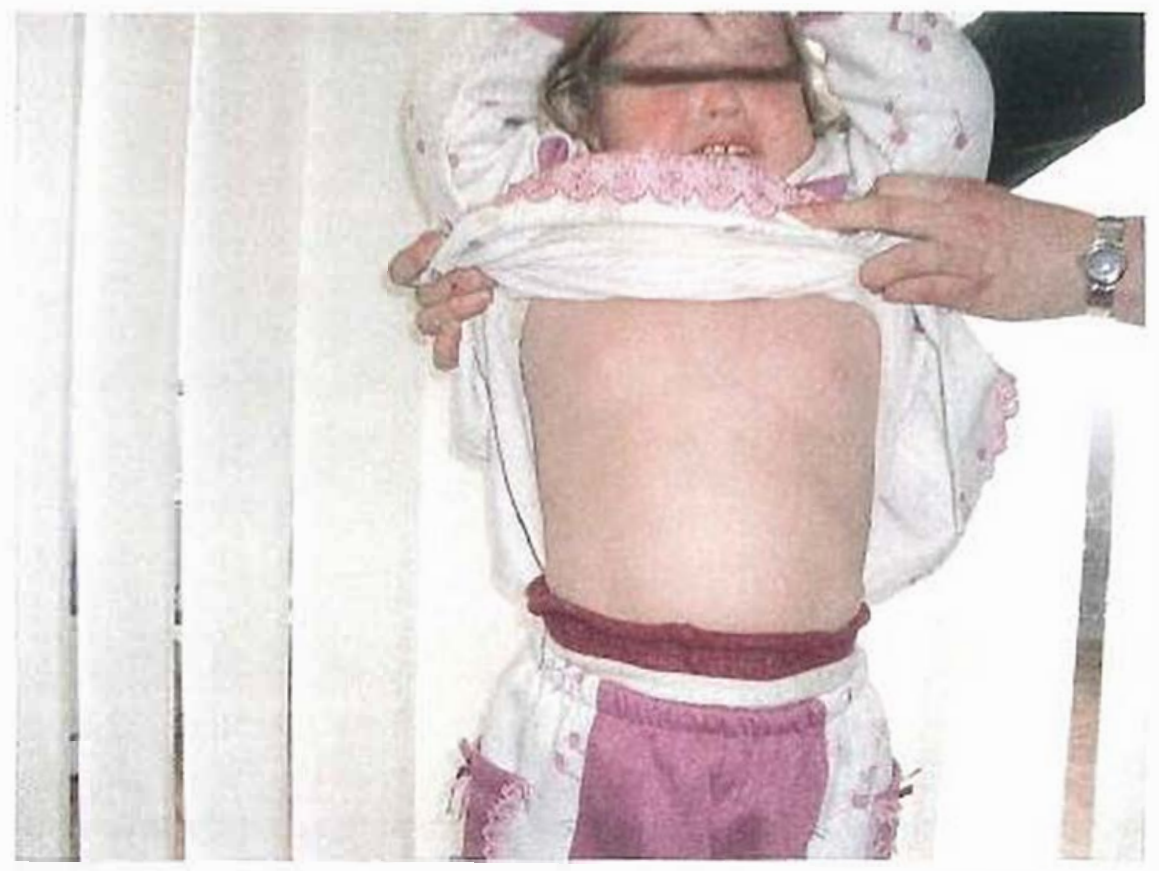

Figure 13. Premature Thelarche in a 4 year old girl.

\title{
Table 4.Causes of premature thelarche
}

\author{
Genetics \\ Increased estrogen sensitivity \\ Increased estrogen (from the adrenal gland, dietary ingestion) \\ Oral contraceptive exposure \\ Transient secretion of estrogen from ovarian follicular cysts \\ Application of estrogen cream to the nipples \\ Transient activation (partial) of pubertal axis with increased FSH \\ Primary hypothyroidism (with elevated TSH and prolactin)
}

Sometimes premature thelarche represents an incomplete and benign form of precocious puberty, requiring periodic observation and reassurance. Early onset of puberty is more common in girls than in boys and is predominantly mediated by premature activation of the hypothalamic-pituitary-gonadal axis (30). Central (true) precocious 
puberty may be caused by hypothalamic hamartomas, trauma, hydrocephalus, and central nervous system lesions; however, it is most commonly idiopathic. Treatment depends on the underlying etiology. Gonadotropin-releasing hormone $(\mathrm{GnRH})$ analogues are used to postpone puberty until an appropriate age and it could be helpful to optimize adult height potential (31).

Peripheral precocious puberty (pseudo-precocious puberty) is due to sex steroid secretion independent of gonadotropin release, and it is much rarer than true precocious puberty; its causes include an estrogensecreting tumor and the McCune-Albright syndrome. When suspecting precocious puberty, tests to obtain include luteinizing hormone ( $\mathrm{LH})$, follicle-stinmlating hormone (FSH), thyroid-stimulating hormone (TSH), thyroxine (T4), testosterone, and estradiol. If premature breast development arises along with other secondary sex characteristics, the diagnosis becomes precocious puberty and a careful evaluation is necessary for underlying organic causes (see table 5). Management is dependent on the underlying etiology. When hirsutism or virilization occurs with precocious puberty, adrenal-tumors or late-onset adrenal hyperplasia must be excluded.

\section{Table 5. Causes of precocious puberty (partial list)}

Idiopathic (80-90\% in females and $40 \%$ in males)

Ovarian neoplasm in females or testicular tumor in males (10\% vs. $15 \%$ respectively)

McCune-Albright syndrome (5\% of females and $1 \%$ of males)

CNS pathology (as neoplasm) (5-10\% in females and 25\%+ in males)

Adrenal neoplasm/hyperplasia ( $1 \%$ in females and $25 \%$ in males)

Hypothyroidism (rare)

\section{BREAST ASYMMETRY}

It is common for young adolescent females to have breast asymmetry; in some youth, one breast bud appears before the other starts while in some youth, asymmetry emerges after bilateral thelarche develops $(4,9)$. Familial or genetic factors influence the timing of 
puberty, the appearance of thelarche, and the rate of breast growth on both sides. Adequate symmetry eventually develops in most females by late adolescence. though approximately $25 \%$ of adult females have visible asymDletry (see figure 14). Padding the smaller side may help while waiting to see if acceptable catch-up growth will take place as adolescence continues. Youth should be advised to avoid worthless "bust developers or pumps" that are sometimes adveltised, though exercise can develop improved pectoralis muscle tone, partially improving the breast appearance. Application of estrogen cream is not recommended by most clinicians since the Jess developed breast may Jack estrogen receptors. Pseudoasymmetry may be present because scoliosis or a rib cage defect gives the illusion of unequal breast size.

Also, a breast may not grow properly because of prepubelial injury, trauma, or surgery that includes improper biopsy of a lesion that is actually a breast bud (1). In very young and preadolescent children, a biopsy should be considered with extreme caution because the developing breast bud may be irreparably harmed, even with a needle aspirate. Thoracostomy tube insertion, anterolateral thoracostomy, infection, and burns may also lead to breast damage. Burns usually lead to scarring with normal underlying breast tissue; the skin contractures should be released by early adolescence to allow normal breast development.

Transient or permanent breast asymmetry can lead to considerable embarrassment and psychological distress. There may be a positive family history for delayed puberty. The small breast may represent partial end-organ failure or the larger breast may be due to a breast mass (see figure 15), as discussed later in this article. Surgery is the typical method of management for significant breast asymmetry when the patient is mature enough to understand the surgical options as well as risks, and provide legal consent. Surgery should be decided on by the youth in late adolescence or early adulthood so the patient is cognitively mature enough to make such a decision and also to allow for full development of both breasts that includes full catch-up growth of the smaller breast. 

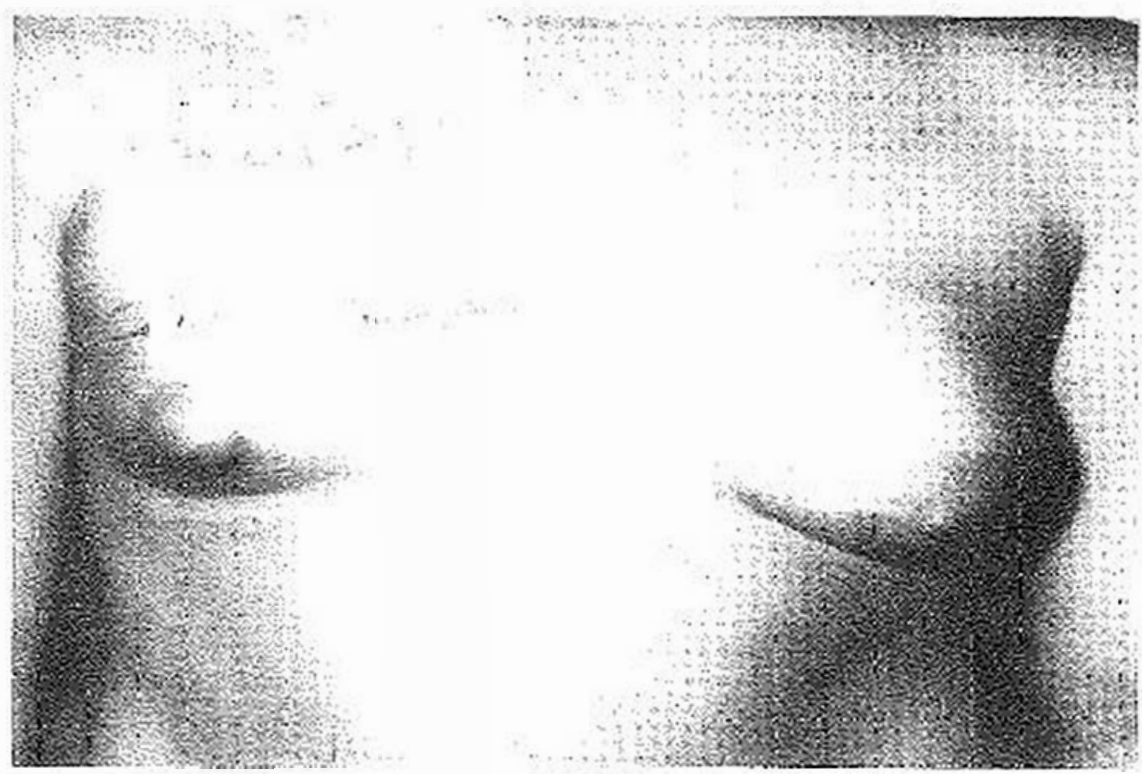

Figure 14. Breast Asymmetry. Of particular interest is the difference in size of the nipple - areolar complex and the overt difference in their location.

Reconstructive surgery includes a combination of augmenting the smaller breast or reducing the larger breast.

One breast may be enlarged and/or the other reduced, depending on the precise situation. Augmentation mammoplasty has been a controversial procedure and the youth should clearly understand the potential benefits and risks associated with the procedure being offered. Surgical complications may include severe scarring, confusion with cancer later in life, and lactation dysfunction; also, innervation of the nipple is from the fourth intercostal nerve and surgical damage to this nerve may lead to loss of erotic sensation [32]. Sometimes it is not the breast volume that is of concern, but the breast shape that requires a breast lift or mastopexy.

\section{UNDERDEVELOPED BREAS'J'S}

Another common concern of some adolescent females is that of small breasts (micromastia; hypoplasia) $(1,2,9)$. It may be found in someone simply in early puberty or in someone in later puberty with an otherwise 
normal examination and normal estrogenization (i.e., normal pubic hair, vagina, uterus, and female appearance), along with a normal menstrual history. Reassurance of normalcy is important, though breast enlargement surgery (augmentation mammoplasty) may be chosen at some point by this patient (32).
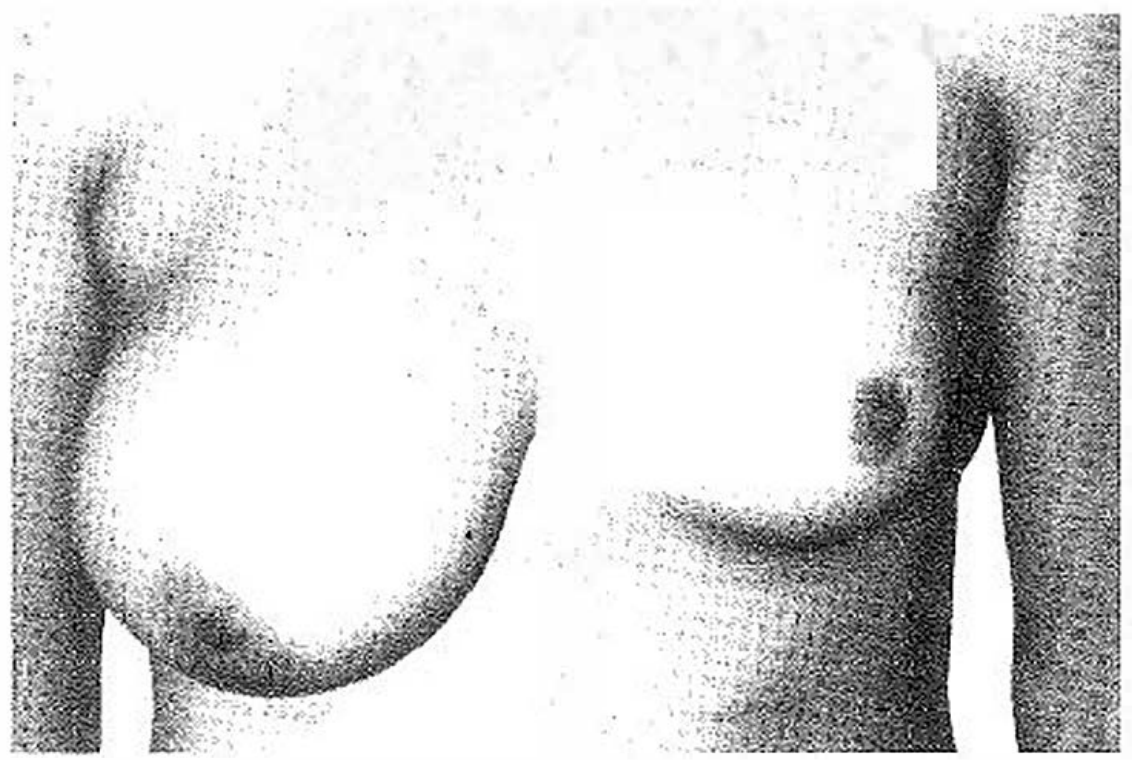

Figure 15. Breast asymmetry due to a right breast lipoma.

However, an evaluation may reveal variable degrees of bilateral hypoplasia or hypomastia plus ovarian dysfunction (see table 6) with failure of secondary sex characteristics and typically primary amenorrhea. The nipple.. are then abnormal as well--less pigmented, less protuberant, and smaller. A complete genetic and endocrine work-up is then recommended. Appropriate management of the underlying disorder is important, as hormonal management of Turner syndrome, for example.

\section{Table 6. Causes of bilateral breast hypoplasia and ovarian dysfunction/hypofunction}

Gonadal dysgenesis (Turner syndrome)

Adrenal hyperplasia (as congenital adrenal hyperplasia) 
Pituitary hypogonadism

Preadolescent hypothyroidism

Androgen-producing tumor

Radiation effects

Bilateral ovariectomy

Malnutrition

Deficiency of body weight $(\mathrm{BMI}<18.5)$

Some chronic illnesses

Delay of sexual development

Amenorrhea

\section{TUBEROUS BREASTS}

An unusual breast deformity has been described by Rees and Aston as tuberous breasts (tuberous breast anomaly) because the breasts have the appearance of a tuberous root plant (see figures 16,17) $(4,33)$. There is limitation in the breast base holizontally and vertically in which the breast projects forward without normal fullness, but with an enlarged, overdeveloped nipple areola complex. Two types are described, Type 1 and 2. Type 1 is the usually tuberous breast presentation with a small concentric breast base and a large nipple areola complex that represents herniation of breast tissue into the areola. The less common type, Type 2, presents with a breast that is more deficient in its vertical than horizontal dimension and has a small breast base. Management of type 1 is with augmentation of these hypoplastic breasts and reduction of the herniated breast tissue from the nipple areolar complex. Type 2 is treated with augmentation of these hypoplastic breasts. Mild cases may not require plastic surgery.

\section{BREAST ATROPHY}

Breast atrophy may develop after thelarcbe from various causes (see table 7) leading to breasts that become wrinkledd, flattened, ptotic, and senile in appearance $(1,2,4)$. Both the adipose and glandular tissues can 
be severely reduced. Restoration of the previous normal breast tissue is unlikely; however, some improvement may occur primarily with correction of the underlying problems and the use of oral contraceptives if appropriate for those with an eating disorder (see figure 18) or other chronic illness. For example, scleroderma can cause variable amount of breast tissue atrophy.

\section{Table 7. Causes of breast atrophy}

Weight loss from severe dieting (especially a protein-poor diet)

Anorexia nervosa

Premature ovarian failure

Scleroderma

Other chronic illnesses causing significant weight loss

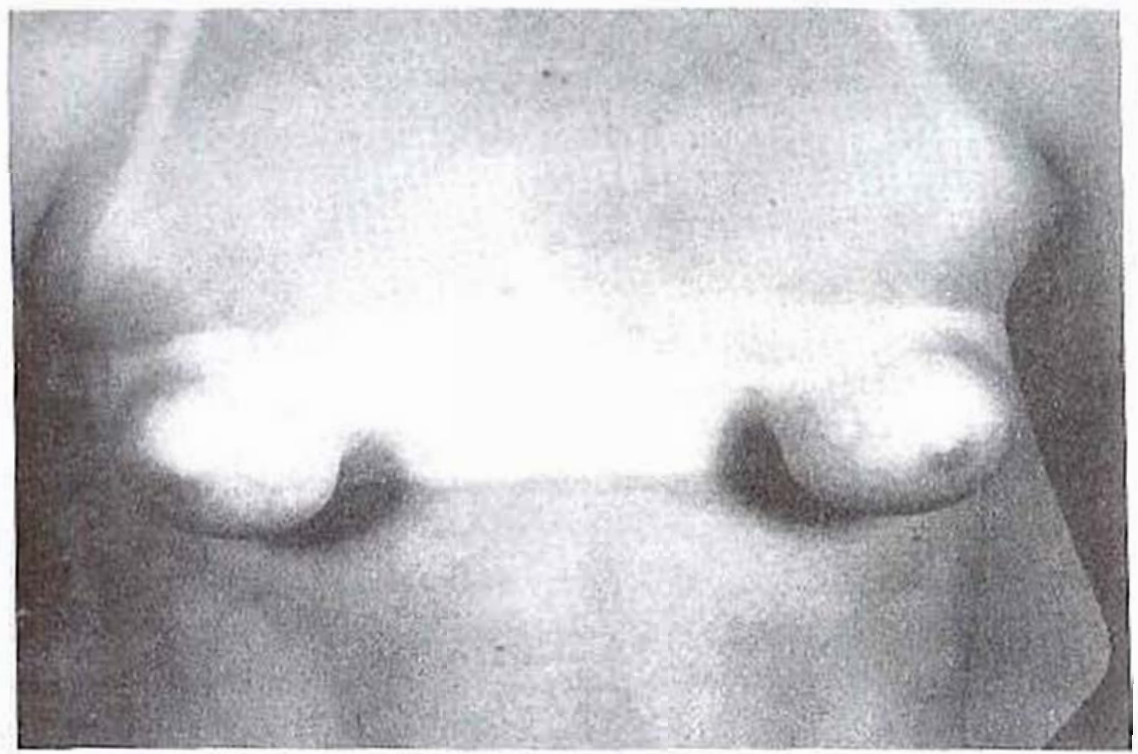

Figure 16. Tuberous Breast Anomaly (Type I). 


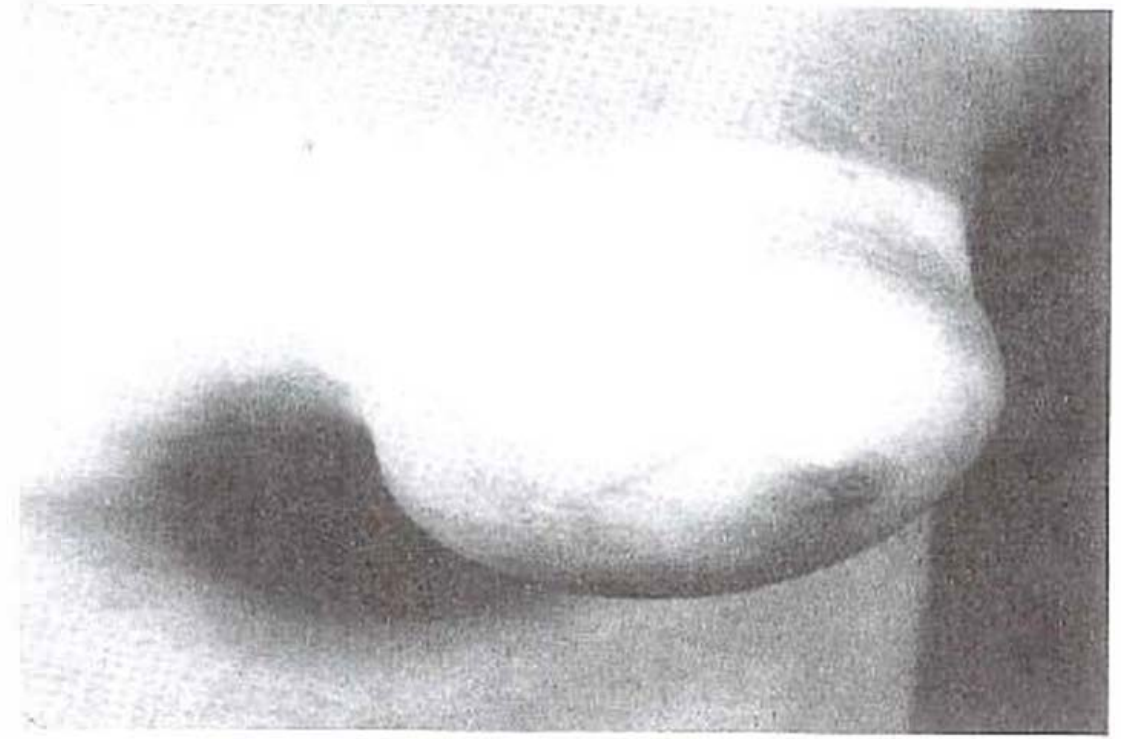

Figure 17. Tuberous Breast Anomaly (Type I). A closer view of Figure 16

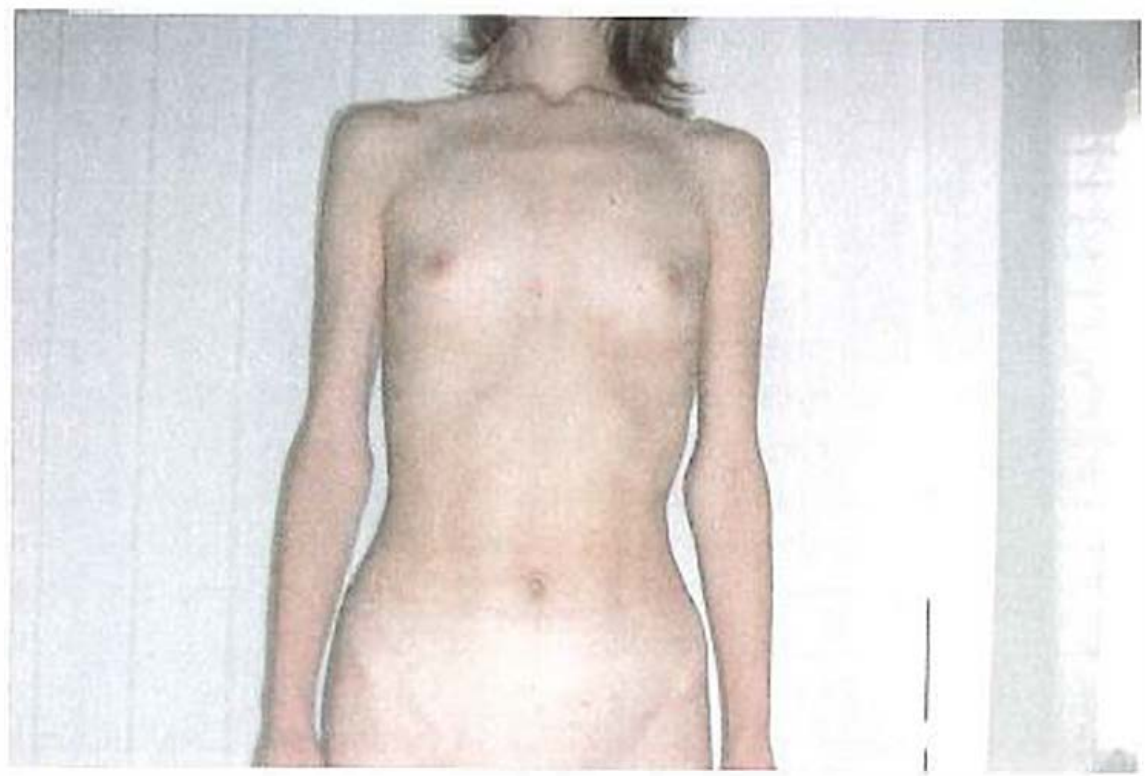

Figure 18. Hypoplosia of breasts in a patient with Anorexia Nervosa, 17 years old. 


\section{MAMMARY HYPERPLASIA}

The condition in which breasts enlarge in the newborn period is called neonatal breast hypertrophy and development of large breasts during puberty has many terms, including mammary hyperplasia or idiopathic breast hypertrophy. Neonatal breast hypertrophy can be noted in as many as $70 \%$ of newborns (females and males) and is usually attributed to maternal estrogen effects ancVor an abnormal ratio of estrogen to androgen. Enlarged breasts are usually less marked in premature infants, presumably since immaturity does not allow as much breast reaction as noted in more mature newborns. The normal post-delivery withdrawal of maternal estrogen can lead to increased prolactin levels and the enlarged breasts in the newborn may produce a clear or cloudy (milk-like) nipple discharge ("witch's milk"). Freq1ent breast stimulation may lead to hyperplasia, nipple discharge, and mastitis. The hyperplasia usually resolves in a few days to few weeks, though there are case reports of breast hypeltrophy lasting up to 10 months in males and 2 years in females. Breast carcinoma in infants with breast hypertrophy is extremely rare.

\section{Juvenile (virginal) breast hypertrophy}

In this situation, there is explosive breast growth often shortly after thelarche that is unilateral or bilateral and often familial (see figures 19,20) (4,34). Extreme growth can rarely be seen and is called macromastia or gigantomastia, as noted by one case report in a 4'10", 106 pound, 12-year-old whose left breast weighed 3,800 grams and right breast weighed 4,200 grams (1). The etiology is usually attributed to heightened response or sensitivity of breast tissue to pubertal hormones and endogenous hormone production from breast cells. Exposure to estrogen has been noted in some cases, as breast hypertrophy developing while on oral contraceptives. It also occurs during pregnancy. Juvenile hypertrophy appears to be more common in African-American females than Caucasian females. Potential sequelae are many, as listed in table 8 $(1,2,9)$. The differential diagnosis of unilateral hypertrophy includes a breast tumor, typically a giant fibroadenoma. 
Table 8. Potential complications of breast hypertrophy
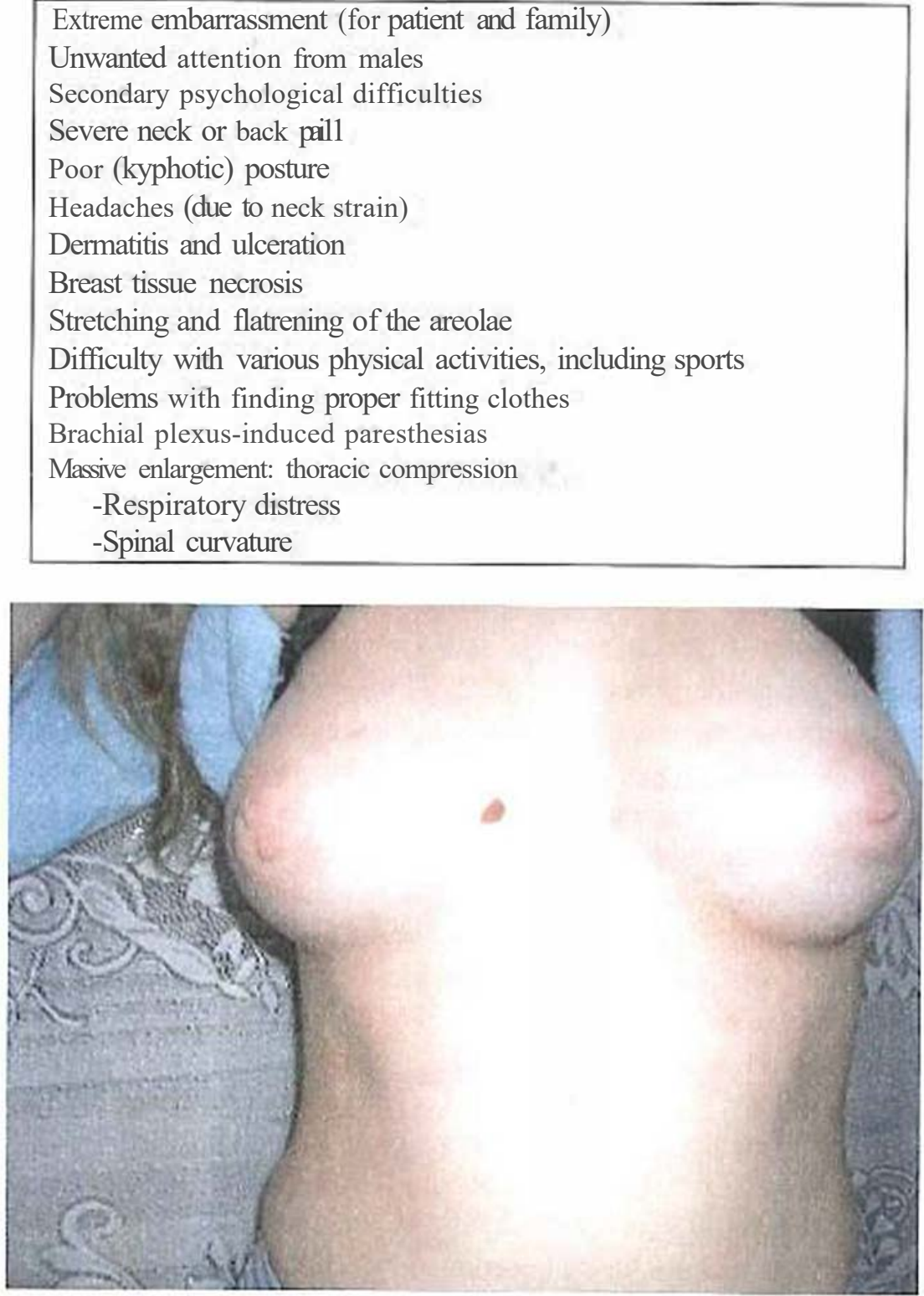

Figure 19. Bilateral Mammary Hyperplasia in a 14 year old girl. Also has polythelia on the right breast 


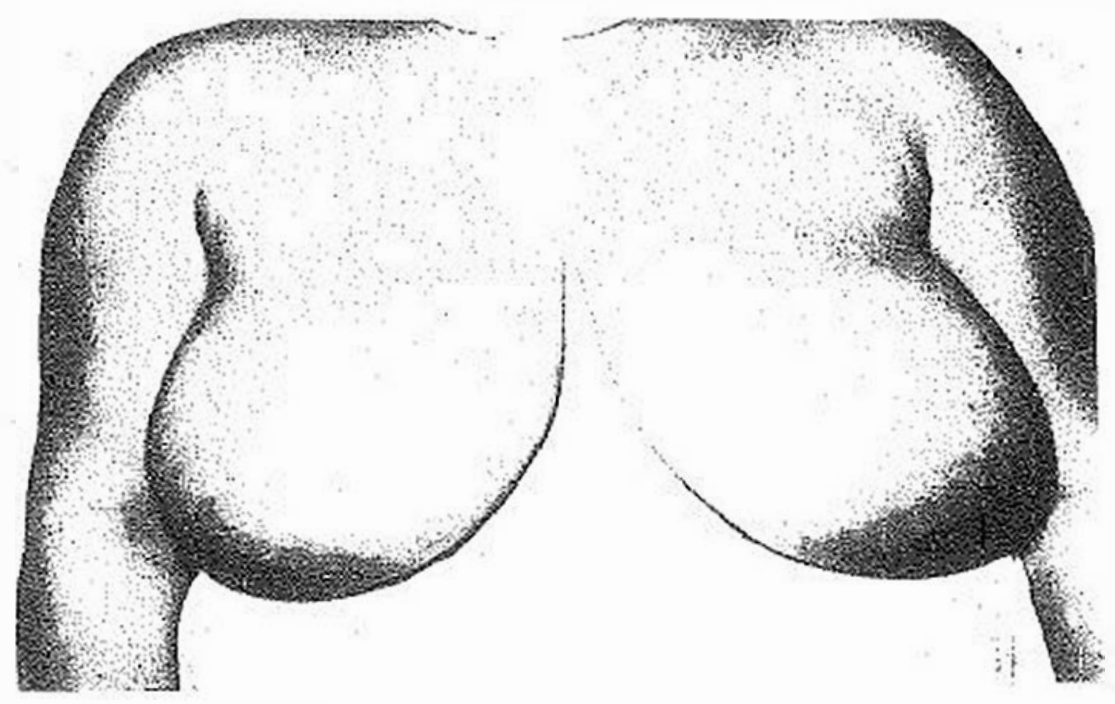

Figure 20. Idiopathic breast hypertrophy in an adolescent.

Management must be individualized and ranges from reassurance that the breast tissue is normal (with firm bra support), to surgery in order to reduce the breast size $(9,35)$. There may be some regression of the hyperplasia later in adolescence, though this is typically mild if at all. Research has noted that medication (such as danazol, medroxyprogesterone, or dydrogesterone) used in adult females is not effective in management of mammary hyperplasia in adolescents and has a number of adverse effects, depending on which medication is used.

It is recommended that surgery, if chosen by the patient, be done at a time when final breast enlargement bas occurred or the breasts are mature and the patient is mature enough to decide if as well as when this surgery should be accomplished (32). Surgery done earlier because of severe problems (se table 8) may be complicated by later recurrent hypertrophy as the breasts continue to grow. The surgery is reduction mammoplasty for unilateral or bilateral hyperplasia and the precise technique depends on the training of the surgeon. Post-operative complications include breast hematoma, infection, wound drainage, and fat necrosis. Other surgical sequelae include breast scarring (can be severe), loss of nipple sensation (5-25\%), and lactation dysfunction. A link between cosmetic breast augmentation and suicide in adult women has been identified (36). 


\section{FIBROADENOMA}

Fibroadenoma is the most common breast tumor in adolescent females, noted in $70 \%$ to $95 \%$ of breast biopsies in this age group; it is the most common cause of a solid breast mass in females from puberty to age 30 $(1,2,4,9,14,22,37-40)$. In Stone's classic series of 165 youth between ages 11 and 20 years, $72 \%$ had a fibroadenoma in contrast to $12 \%$ with hyperplasia, $7 \%$ with an abscess, $6 \%$ with breast cystic disease, and $3 \%$ with intraductal papilloma (41). In Hein's review of 95 adolescents, $75 \%$ with biopsies had a fibroadenoma, in c:ontrast to $12 \%$ with an abscess, $10 \%$ with cystic disease, $2 \%$ with a lipoma, and $2 \%$ with cystosarcoma phyllodes (42). Table 9 provides a list of breast mass pathology.

A fibroadenoma typically presents as a rubbery, non-tender, encapsulated mass slowing increasing in size over weeks to months (see figure 21). Sometimes it is seen as an irregular or oval lump with a consistency that can vary from elastic to hard versus the typical rubbery type; nipple discharge is not noted. The lesion can be seen anywhere in breast tissue, though the upper, outer quadrants are the most common. It usually is $3 \mathrm{~cm}$ to $4 \mathrm{~cm}$ when found, but can continue to enlarge to 10 or $15 \mathrm{~cm}$ if not removed in time. Large lesions can induce a malignancylike state with peau d' orange skin having erythema and enlarged veins overlying the tumor. Bilateral or multiple tumors, often called fibroadenomatis, are noted in $10 \%$ to $25 \%$ of cases.

\section{Table 9. Causes of breast masses*}

\begin{tabular}{|l|l|}
\hline Fibroadenoma & Miscellaneous \\
\hline Juvenile (giant) fibroadenoma & Nipple adenoma \\
\hline Other fibroadenoma variants & Papillomatosis \\
\hline Virginal hvoernlasia & Ductal adenocarcinoma \\
\hline Cystosarcoma phyllods & Mammary duct ectasia \\
\hline Breast abscess & Intraductal oranuloma \\
\hline $\begin{array}{l}\text { Breast cyst (including fibrocystic } \\
\text { Breast disease and other Breast } \\
\text { mastopathies) }\end{array}$ & Sclerosing adenosis \\
\hline Breast carcinoma & Keratoma of the nipple \\
\hline Intraductal papilloma & Interstitial fibrosis \\
\hline Fat necrosis & Granular cell myoblastoma \\
\hline
\end{tabular}


274 Donald E. Greydanus, Hatim A. Omar, Lyubov Matytsina et al.

\begin{tabular}{|l|l|}
\hline Lipoma & Angiosarcoma of the breast \\
\hline \multirow{4}{*}{ Lymphangioma } & $\begin{array}{l}\text { Metastatic disease (e.g., } \\
\text { leukemia, malignant lymphoma, } \\
\text { ovarian malignancy, others) }\end{array}$ \\
\hline Hemangioma & Neurofibromatosis \\
\cline { 2 - 2 } & Dermatofibromatosis \\
\cline { 2 - 2 } & Tuberous mastitis \\
\cline { 2 - 2 } & Papilloma sarcoidosis \\
\cline { 2 - 2 } & Hematoma \\
\cline { 2 - 2 } & Others \\
\hline
\end{tabular}

- With permission from Greydanus DE. Breast and gynecological disorders" In: Hofmann $\mathrm{AD}$, Greydanus $\mathrm{DE}$, eds. Adolescent medicine, $3^{\text {rd }}$ ed. Stamford, CT: Appleton Lange, 1997:524.

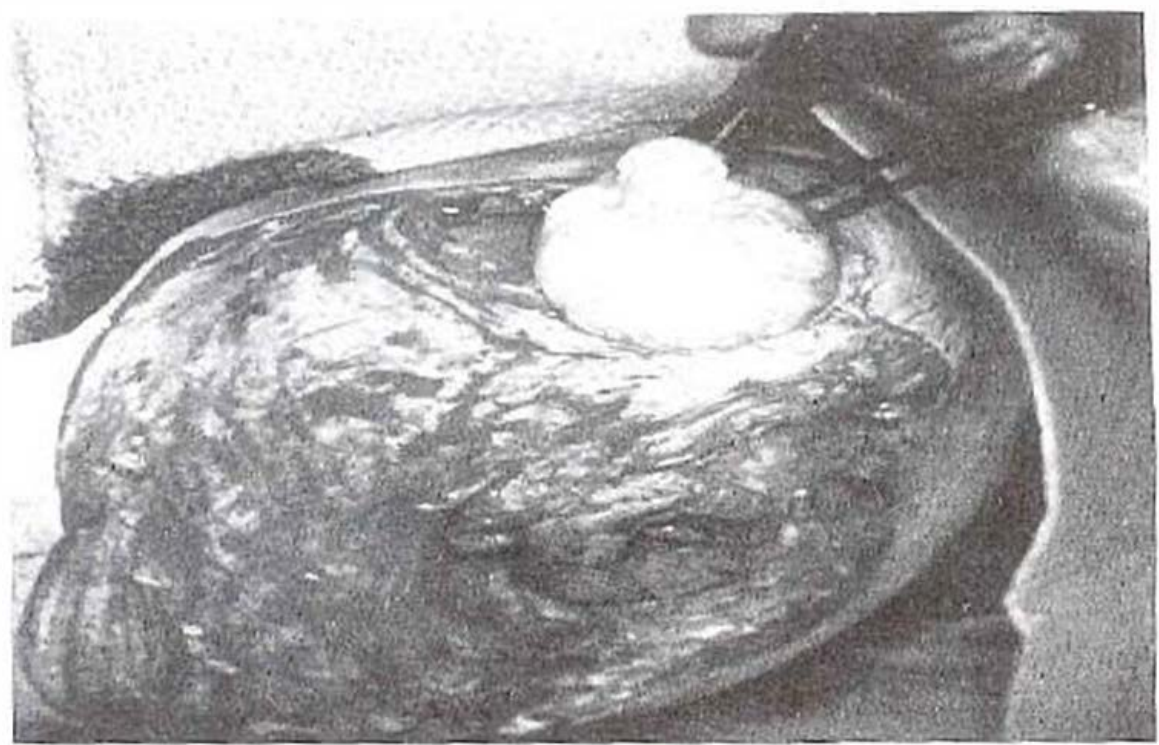

Figure 21. Fibroadenoma. Lesions can be diagnosed by needle aspiration and effective treatment is total excision. For needle biopsy, use a $1^{1 / 2}$-inch 22 -gauge needle attached to a 12-ml syringe and use aseptic technique. Fix the mass between your fingers and place the needle into it. Entering a fibroadenoma, as this one, is like placing a needle into a rubber eraser, while entering breast cancer, the aspirator notes firm resistance and acharacteristic feeling while entering microcalcifications of the tumor. A "popping" sensation is felt while the needle enters acyst as the mass disappears. 
Fibroadenomas are estrogen-sensitive tumors that can develop from breast lobules and stroma at any time during adolescence, from 2 years before menarche to the more typical late adolescence liming of 17 to 20 years ofage; estrogen receptors are found in this tumor. Development of these tumors tends co decrease by the mid-to late 20s (22). It is found in all ethnic groups, though it is more common in African-American females. Enlargement may occur late in a menstrual cycle and especially during pregnancy; spontaneous regression may occur, but is not the norm. The typical biopsy reveals a pattern similar to virginal hyperplasia and male gynecomastia with ducts that are elongated in a stroma that is fibrous (see figures 22-24): a number of histologic variants are noted and classified according to tumor size and stroma cellularity $(1,2,4)$. Figure 25 reveals the ultrasound appearance of fibroadenomas.

Used with permission from Jeffrey Pearson. MD. Medical Director, Pathology Department, Bronson Hospital, Kalamazoo, Michigan.

Figure 22. Fibroadenoma Histology. 


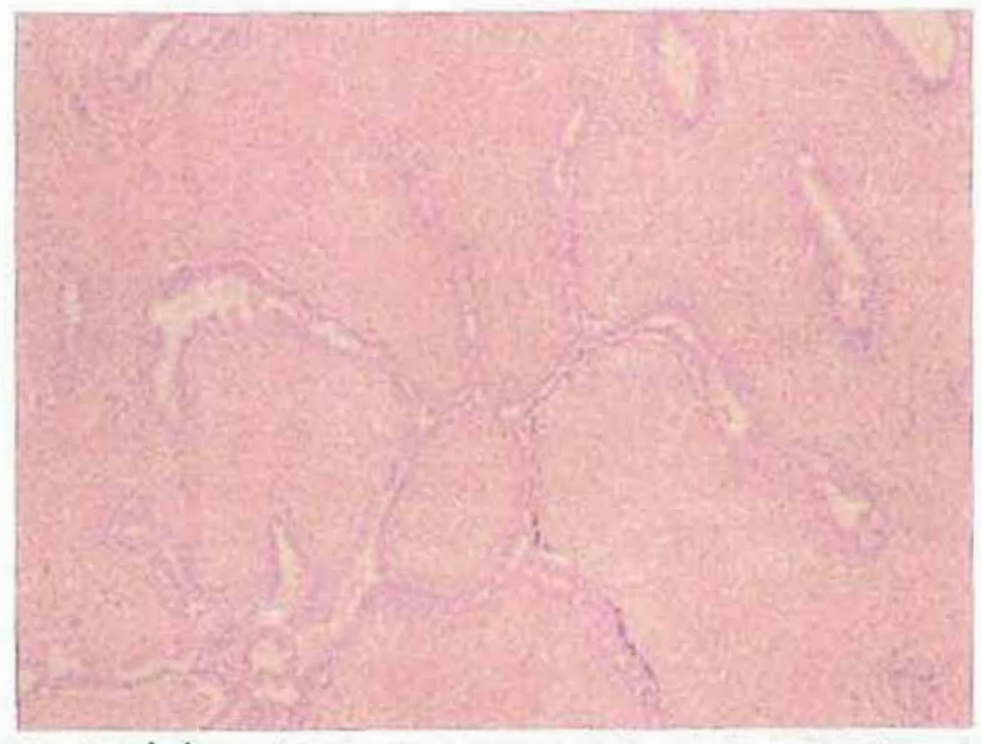

Used with permission from Jeffrey Pearson, MD, Medical Director, Pathology Department, Bronson Hospital, Kalamazoo, Michigan Figure 24. Fibroadenoma Histology.

Figure 23. Fibroadenoma Histology.

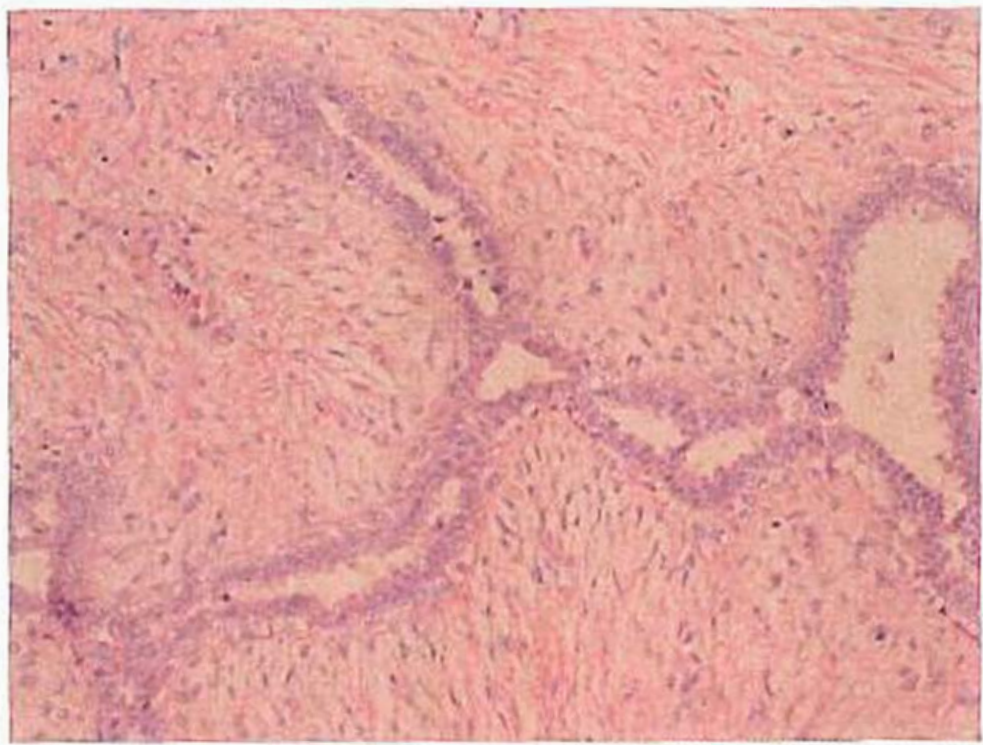

Used with permission from Jeffrey Pearson, MD. Medical Director. Pathology Department, Bronson Hospital, Kalamazoo, Michigan

Figure 24. Fibroadenoma Histology. 


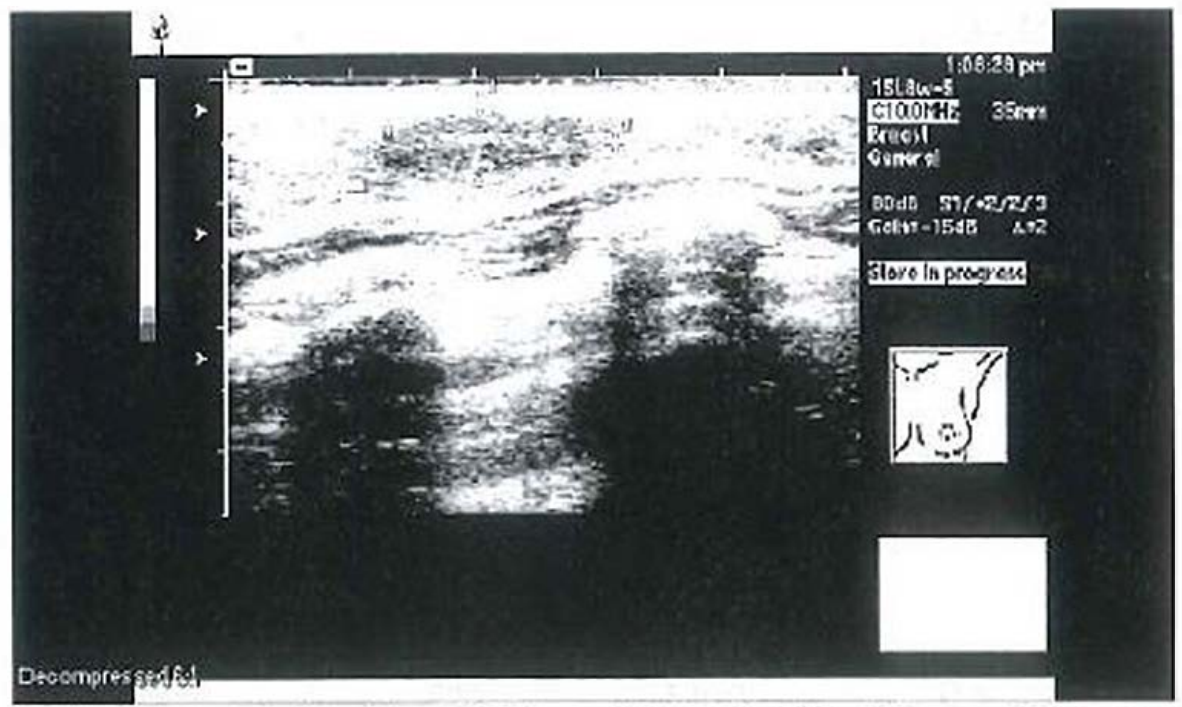

Used with permlsslon from Kathleen Gadwood, MD, Ultrasound Division, Radiology Department. Bronson Hospital, Kalamazoo, Michigan.

Figure 25. Ultrasound: Fibroadenoma. 13 year old, left breast masses. The patient presents with two palpable masses in the medial and inferomedial left breast. On palpation, these masses are freely movable with a rubbery consistency. They are nontender. Targeted ultrasound shows the largest mass located medially is oval, well-circumscribed with a thin capsule, long axis parallel to the skin, measuring $3.3 \times 3.3 \times 0.8 \mathrm{~cm}$. This is located in a very thin portion ofbreast tissue. The other nodule is located just medial and inferiorly, and measures $1.9 \times 1.1 \times 0.8 \mathrm{~cm}$. This has a similar echo appearance. Impression: Benign findings. The sonographic appearance would be consistent with two fibroadenomas.

Though the differential diagnosis of a breast mass or lesion in an adolescent is quire extensive (see table 9), the diagnosis of fibroadenoma is usually considered in typical presentations. Malignancy is often the concern of the patient and her parents; fortunately, this is quite rare in the adolescent population and there is no proven link between the presence of a fibroadenoma and later breast cancer development $(4,44)$. The timing of the tumor removal varies according to the tumor's presentation, size (some consider surgery only if the tumor size is $>2 \mathrm{~cm}$ ), concern of the patient and/or parents, how quickly the lesion grows, and other factors. It is not possible to predict the growth of a fibroadenoma; some spontaneously involute over several months, some grow slowly, and some remain dormant for many years. 
Discrete breast masses should almost always be removed in boys and postpubertal girls. Excisional biopsies are usually performed using a circumareolar incision; if the mass is distant from the areola, an incision directly overlying the mass may be performed. A small and slow. growing lesion in an adolcscent female that is rubbery and non-tender can be observed over 2 co 4 months. Novel non-s1croidal selective antiestrogen drugs have also been administered in those with fibroadenoma, with a reported result of $40 \%$ disappearance and $20 \%$ partial regression (43,45). Minimally invasive procedures for management of fibroadenoma include percutaneous radiofrequencyassisted lexcision and cryotherapy $(46,47)$.

One should certainly not wait until the lesion is large, as this may require more extensive surgery to remove the tumor, increasing the risk of breast deformity, and making skin closure more difficult. Expert surgical technique is important for the youth with a young, growing breast; for example, protection of the developing nipple, areola, and other breast tissue is as important as excision of the lesion. Waiting until the tumor is large may also require additional surgery to reduce the skin envelope and elevate the nipple for a good cosmetic result. If a unilateral lesion presents, excision, biopsy can rule out cystic breast disease, virginal hypertrophy, cystosarcoma phyllodes and other conditions. A lesion that enlarges rapidly must be distinguished from virginal hyperplasia, giant fibroadenoma, and cystosarcoma phyllodes. If a patient presents with fibroadenomatosis, the largest lesion should be removed to establish the diagnosis and prevent breast deformity. If there is evidence of malignancy, immediate investigation with complete lesion removal is indicated.

\section{GIANT (JUVENILE) FIBROADENOMA}

The giant or juvenile fibroadeaoma is larger than $5 \mathrm{~cm}$ in diameter, somelimes doubling in size within 3 to 6 months, up to 15 or $20 \mathrm{~cm}$; it may compress or replace normal breast tissue (see figures 26 and 27) $(1,2,4,9)$. It is less common than the normal fibroadenoma, but, like the typical fibroadenoma, the giant variant is more common in AfricanAmerican youth and peaks in incidence in late adolescence; it tends to be 
more common than the smaller version in the young adolescent and its consistency tends to be softer than the rubbery consistency of the smaller fibroadenoma. Adjacent breast tissue can be compressed and distorted by the size and rapidity of growth of a giant fibroadenoma, leading to overlying skin ulceration.

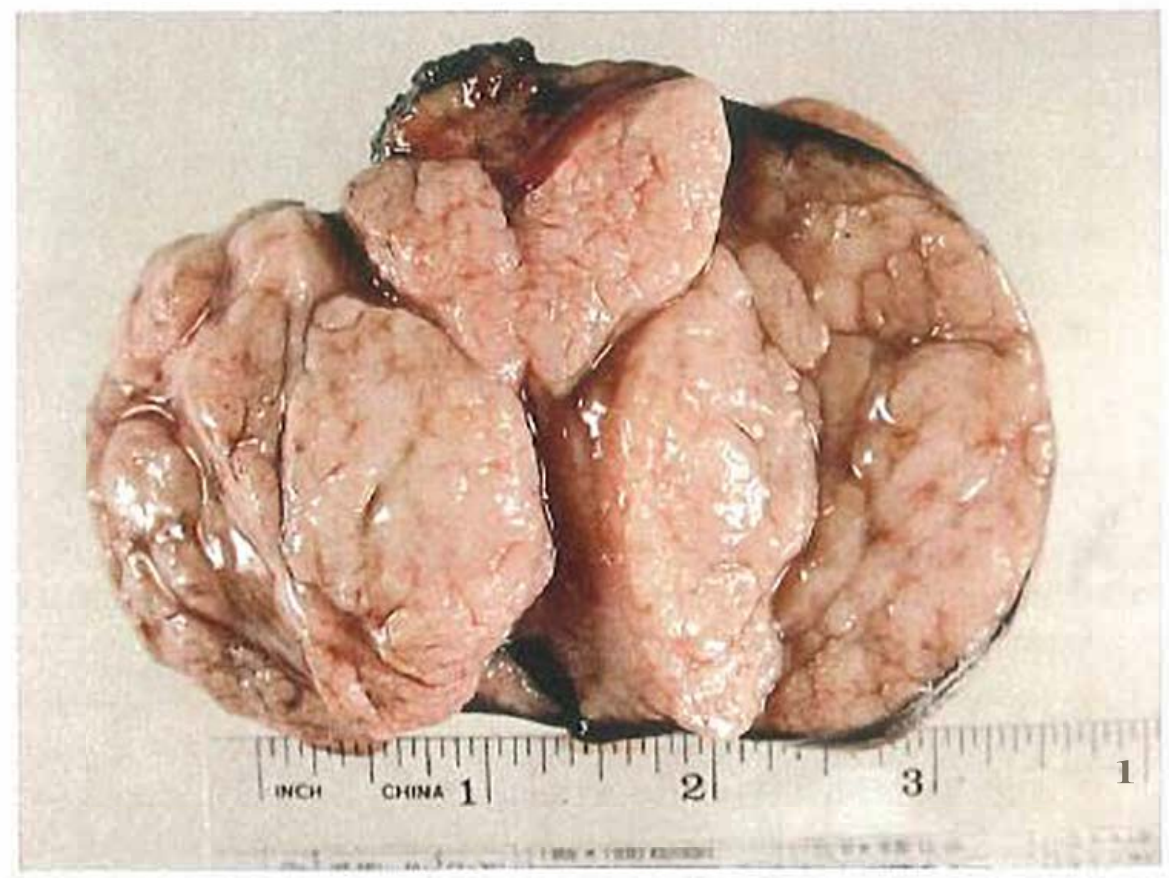

Used with permission from Jeffrey Pearson, MD, Medical Director, Pathology Department, Bronson Hospital, Kalamazoo, Michigan.

Figure 26. Giant (Juvenile) Fibroadenoma.

Complete removal of a large lesion may be difficult because of its size and the difficulty separating out normal tissue margin from tumor margin. A number of histologic variants are described and are sometimes confused with cystosarcoma phyllodes. The typical biopsy of a giant fibroadenoma reports increased stromal cellularity and fibrosis. The lesion can be single, recurrent, or even found posterior to breast tissue; in the later case, the larger breast has increased warmth because of increased blood in the tumor and distended veins overlying the involved skin. A tumor with severe atypical epithelial hyperplasia may cause confusion with malignancy. 


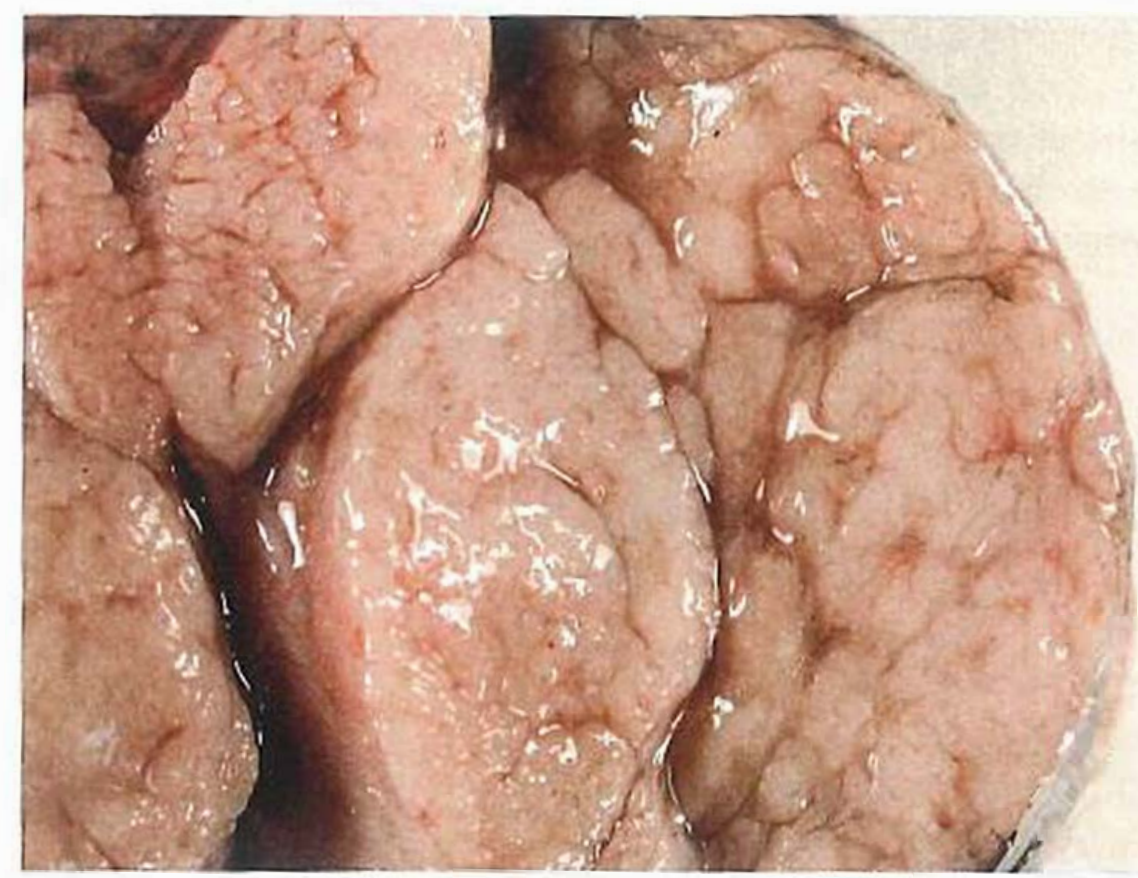

Used with permission from Jeffrey Pearson, MD, Medical Director, Pathology

Department, Bronson Hospital, Kalamazoo, Michigan.

Figure 27. Giant (Juvenile) Fibroadenoma.

\section{Cystosarcoma PHYLLODES}

Though breast malignancy is rare in the adolescent, the main type noted is cystosarcoma phyllodes (phylloides; Greek: phullon leaf) $(1,2,4,9,14,48,49)$. Its original description by Muller in 1838 included the idea that this tumor arises from a fibroadenoma, leading to many decades of linking these two lesions $(1,2)$. At present, there is no evidence cystosarcoma phyllodes arises from a fibroadenoma. Proposed etiologic factors for cystosarcoma phyllodes include pubertal hormonal effects (including excess estrogen), pregnancy, lactation, and trauma. It can be associated with a variety of tumors, such as intraductal breast carcinoma, Brenner tumor of the ovary, desmoid tumor, and scirrhous breast carcinoma. 
Cystosarcoma phyllodes can be found in all decades of life, peaking in the fom $1 \mathrm{~h}$ decade. In adults it represents 0.3 to 0.9 percent of all breast tumors and though most are benign, metastatic disease is found in 3\% to $12 \%$ (or more). Approximately $5 \%$ to $8 \%$ of cases occur in those under age 20, mainly between ages 16 and 19 years of age and most are benign $(1,2,48)$. However, rare cases of malignant disease with death are reported in the literature in adolescent females as well as cases of cystosarcoma phyllodes in prepubertal children and even adolescent males with gynecomastia.

Cystosarcoma phyllodes usually presents as a painless, slow growing breast tumor that is typically $8 \mathrm{~cm}$ to $10 \mathrm{~cm}$ when found. However, its growth may be explosive and symptoms are dependent on the size and location of the tumor. There may be a large tumor (up to $20 \mathrm{~cm}$ ) with overlying shiny skin that is stretched and contains distended veins, erythema, and skin ulcers. There can also be local tissue compression (with parenchyma necrosis), nipple retraction, bloody nipple discharge, and in 20\% of cases-axillary lymphadenopathy (from infection and tumor necrosis, not usually overt metastasis). In the unusual adolescent case with tumor metastasis, spread is hematogenous and the lung is the most common area involved, though any organ invasion is possible. The tumor size does not reflect malignancy and three basic histologic patterns are described: benign, intermediate (borderline), and malignant.

A benign type has less encapsulation and more cellular stroma than a fibroadenoma; a malignant lesion has cellular atypia, anaplasia, and mitotic activity.

An ultrasound may give a fibroadenoma-like appearance or give a cystosarcoma phyllodes-like appearance of fluid-filled, elongated spaces or cleft within a solid tumor. As previously noted, mammograms are usually not helpful in adolescent females because of their dense breast tissue. Management depends on total rumor removal, results of the histologic study, and evidence of metastasis. The tumor must be fully excised, leaving margins free of tumor and tumor appendages. 1lle management of intermediate or overt malignant cases remains controversial and the prognosis is often poor. Various treatments are used including radical surgery, chemotherapy, radiation therapy, and hormonal trea01lent $(1,2,4,9,14,48,49)$. 


\section{INTRADUCTAL BREAST PAPILLOMA}

This is a rare tumor in the adolescent population, usually presenting as a small lesion under the areola that produces sanguineous or serosauguineous discharge from the nipple $(1,2,4)$. It may be quite small and only found with careful palpation in the subareolar area. Sometimes a tumor is not felt, but palpation compresses a duct that is distended with the tumor, leading to the typical nipple discharge. Intraductal breast papilloma is bilateral in $25 \%$, and cytology of the nipple discharge notes clusters of ductal cells. Table to lists the differential diagnosis of intraductal breast papilloma. Helpful diagnostic aids include ultrasound and fine needle aspiration. Intraductal breast papilloma is a benign lesion (though some experts classify it as a pre-malignant condition) and local excision cures the condition. Infiltrating ductal adenocarcinoma is a very rare malignant disorder in adolescents that requires radical mastectomy and radiation therapy.

Table 10. Differential diagnosis of intraductal breast papilloma

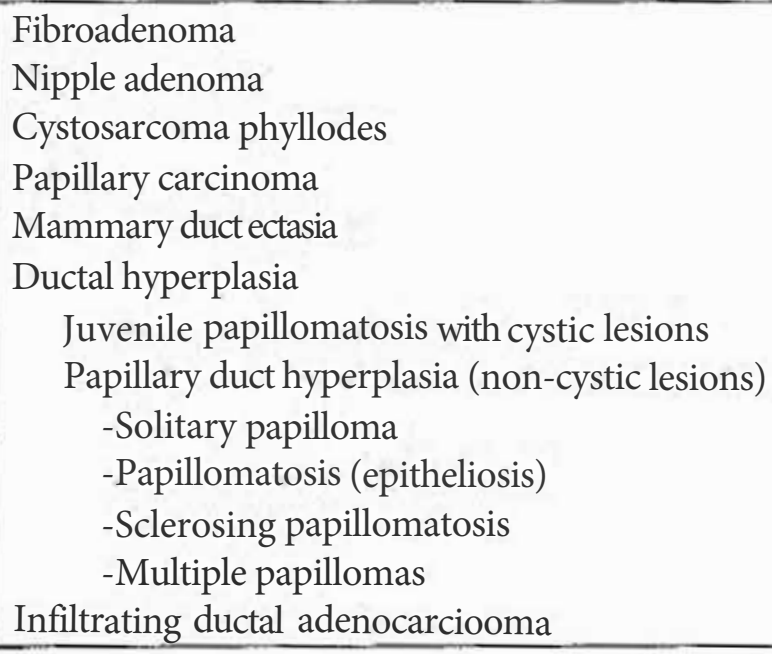

Mammary duct ectasia (periductal mastitis) presents with a nipple discharge (dark-brown) because of dilatation or ectasia of ducts behind the nipple; there can be a painful subareolar nodule with nipple retraction, sinus tracts or fistulae, and axillary lymphadenopathy. It is the 
most common cause of nipple inversion and there can be infection with Bacteroides sp. Management includes antibiotics, sinus tract/fistulae excision and sometimes, excision of part or all of the involved nipple.

\section{BREAST CANCER}

Breast cancer (i.e., adenocarcinoma) is a rare disorder in adolescent females; however, it is on the mind of the patient (and parents) when she presents with a breast mass $(1,2.4,50-53)$. Breast cancer is found in less than $2 \%$ of females under age 25 , less than $1 \%$ in those under age 20 years of age, and rarely in those under 15 years of age. However. it is reported in youth and very rarely in prepubertal children, and thus, must be part of the differential diagnosis of a breast mass in children and adolescents. In very rare cases it has been reported in males $(52,54,55)$.

Risk factors are noted in table 11 and improved prognostic factors in table $12(1,2,9,14,56)$. A positive family history for breast cancer is a very high risk factor (30-50\%), especially with certain syndromes, as noted in table 9. Those with BRCA1 or BRCA2 gene mutations are noted in 8 of 10 familial breast cancers and $5 \%$ of all breast cancers $(1,2,9,56)$. The decision to test for these gene mutations in female adolescents with a positive family history for breast cancer is based on various factors including the age of the adolescent, legal consent issues, and others. Though controversial, there is no clear link between the use of oral contraceptives and later development of breast adenocarcinoma (57). However, breast cancer is found in association with other cancers, as that of the ovary, uterus, and colon. Two-thirds of breast cancer found in adolescents are malignancies arising in non-breast tissue, such as secondary sarcomas (fibrosarcoma or liposarcoma) and metastatic disease due to lymphoma, leukemia, Hodgkin's disease, or multiple myeloma $(57,58)$. 


\section{Table 11. Risk factors for breast cancer*}

Positive family history of breast cancer Nulliparous status; not breast-feeding -BRCAL (chromosome 17q) Benign breast disease (see text) -BRCAZ(chromosome 13q) (HRT)

Hormone replacement therapy

(especially HRD

?Oral contraceptive pill?

Miscellaneoos syndromes

SBLASyndrome(Li-Fraumani)

(especially the chest)

Cowdcn's Syndrome

(proposed)

Muir Syndrome

Klinefelter syndrome (males)

Others

consumption

Early pubatyand early menarche

(as Hodgkin's disease)
Delay of first pregnancy (after age 30)

Radiation exposure

Increased dietary fat

Obesity (proposed)

Moderate or more alcohol

History of childhood cancer

- Usedwith permission from: Greydanus DE, l'arl(s D, Farrell E.Disorders of !hebreasts in children and adolescents. Pediatr Clin NorthAm1989;36(3\}:625. *Used with permission from:

Table 12. Good prognostic factors for breast cancer*

Stages I and II

(Stage I: tumor is under $2 \mathrm{~cm}$ in diam.eter and there are $\mathbf{J}$ lymph nodes or distant metastasis: Stage II: tumor is under $5 \mathrm{~cm}$ in diameter. the palpable lymph nodes are not fixed, and there is

no distant metastasis).

Positive estrogen rece.ptor status

Secretory histology type

Circumscribed tumor edge (versus infiltrative)

Lateral location (versus medial)

Tumor under $2 \mathrm{~cm}$ in diameter

Absence of lymphadenopathy, nipple involvement, and cutaneous inflammatory changes

-Used wilh permission from: Greydanus DE, Parks D, Farrell E. Disorden; of the breasts in children and adolescents. Pediatr Clin North Am 19\&9;36(3):625. 
Though breast cancer is rare in the adolescent., it does exist and this risk increases considerably as she enters her adult years (see figure 28). Issues of self-breast examinations in adolescent females have been considered earlier. Screening mammograms are not helpful in most youth because of their normally dense breast tissue, as previously noted (see figure 29). The role of prophylactic mastectomy for those considered at high breast cancer risk should be made in consultation with a gynecologist recognized in this area; it is a controversial step, but one that patients can consider. Adult females with benign breast disease that increases their risk for breast cancer may be offered prophylactic tamoxifen (22).

Adenocarcinoma presents in the adolescent female as a non-tender, indurated, hard, single mass; it has indistinct margins, is typicallȳ fixed in the breast tissue or chest wall, and ranges from $1 \mathrm{~cm}$ to $9 \mathrm{~cm}$ at discovery. There may be skin edema, (peau d'orange), nipple discharge, retraction of the skin or nipple, and/or lymphadenopathy (axillary or supraclavicular). Metastatic disease may induce generalized skin rash, dyspnea (with pleural effusion), upper or lower limb swelling, back pain, hepatomegaly, and/or other features indicating spread of the primary cancer. A variety of diagnostic procedures are used, including mammography, ultrasonography, thermography, and DTPA breast scintiscanning. A CT or MRI can be helpful to differentiate a breast mass from a rib le-sion or other chest wall pathology, or identify normal tissue (versus a mass, including a hemangioma or lymphangioma). The most reliable way to differentiate breast cancer from more common benign breast masses is the triple assessment, including palpation, radiology (mammography, ultrasound, and MRI scan), and fine-needle aspiration cytology (59).

An open or closed biopsy obtains tissue for a definitive pathological diagnosis, noting whether the cancer has developed from the secretory part of the breast (lobules) or the duct connecting the lobules to the nipple; it can be invasive or in situ. As noted, the cancer is an adenocarcinoma, often secretory, though other types are also less frequently identified (i.e., papillary, medullary, infiltrative, serous, glandular, inflammatory, colloidal, and mixed). Metastatic disease may develop, involving bone (often the back), lungs, liver, and other sites; it can be monitored with a variety of biochemical markers, such as 
carcinoembryonic antigen, alkaline phosphatase, and hydroxyproline. Breast sarcomas and secondary malignancies (from leukemia or malignant lymphomas) are rarely noted as well. There may be a second cancer in an adolescent whose first cancer (i.e., leukemia, non-Hodgkin's lymphoma) occurred when the patient was a child, a metastatic neuroblastoma, a cancer due to previous chest wall radiation, and others. Management should be under the care of a specialist trained in current techniques of treatment, as well as understanding of the adolescent patient and her family.

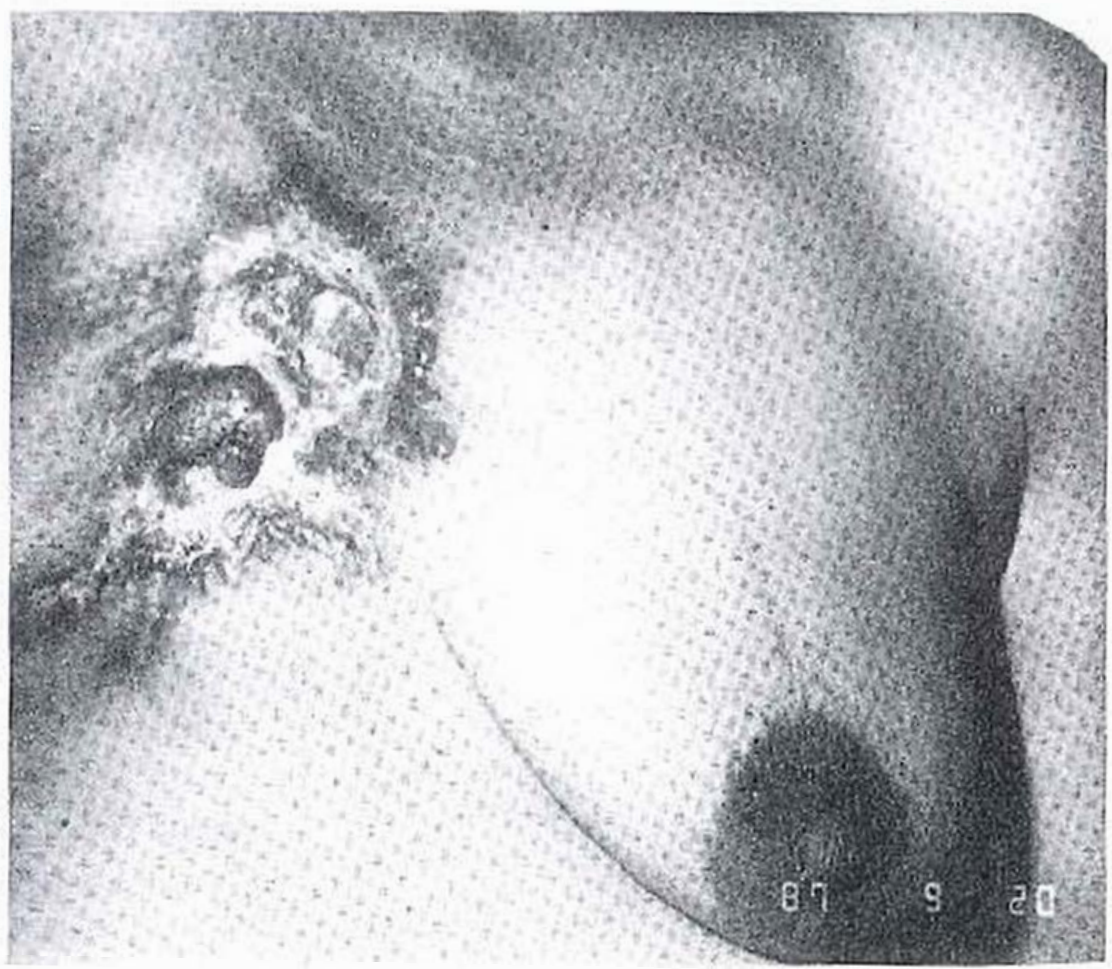

Figure 28. Breast Cancer. 


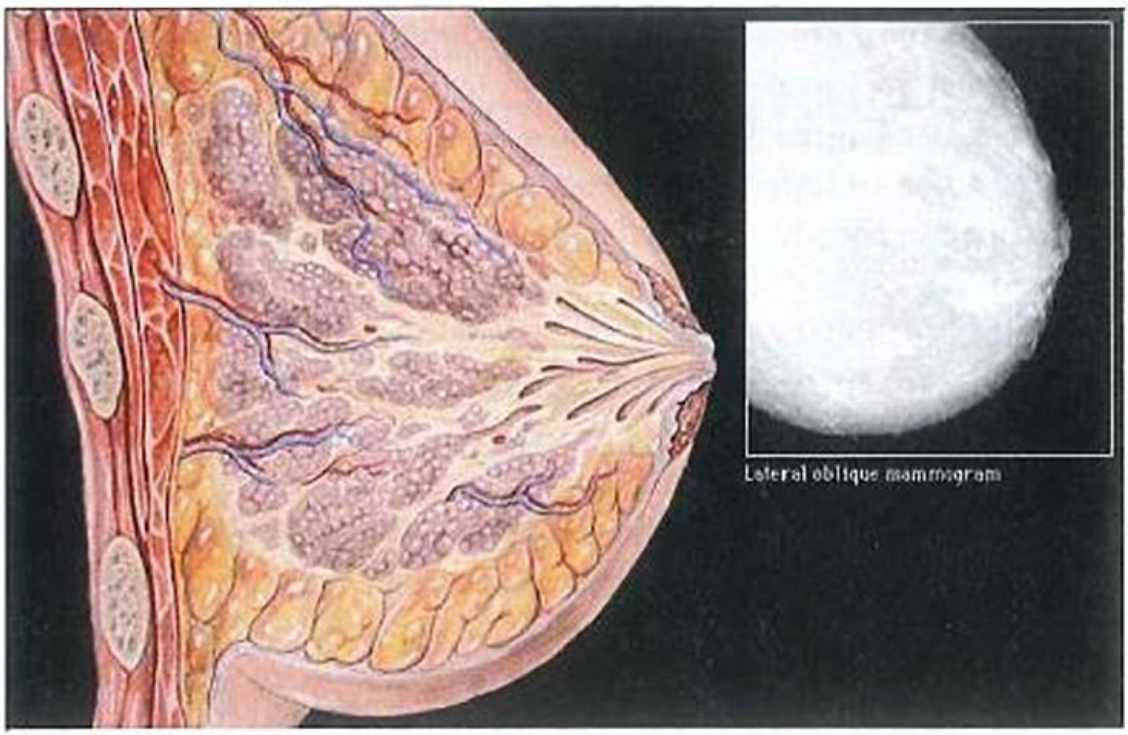

Figure 29. Breast Anatomy and Mammography.

\section{BREAST INFECTIONS}

\section{Pre-pubertal infections}

Neonatal breast hyperplasia can be complicated by infection from too much clinician examination or over-manipulation, as noted earlier. Mastitis can develop in neonates (mastitis neonatorum) involving the entire breast bud and can be complicated by septicemia $(1,4,9)$. Mastitis can also develop in the prepubertal child, though septicemia does not usually occur. Antibiotic therapy is important to help resolve this infection in both newborns and children. The most common organism causing breast abscesses in this population is Staphylococcus aureus. Recently, an increasing number of skin and soft tissue abscesses caused by community-acquired methicillin-resistant Staphylococcus aureus (MRSA and other variations) have occurred in children.

Treatment involves antibiotics, needle aspiration, or surgical drainage. The literature suggests that drainage alone. without adjunctive antibiotics, may be effective for skin and soft tissue abscesses caused by MRSA; no definitive antibiotic recommendation exists regarding MRSA 
breast abscesses (60). If an incision and drainage-procedure is used, a circumareolar incision is recommended to avoid damage to the breast bud tissue, leading to later reduction iJ1 adult breast size; it is also important to avoid removing the entire breast bud, which can happen, if concern is raised about a "lesion" that may be the breast bud!

\section{Post-pubertal infections: Lactational mastitis}

Breast infection or mastitis in the adolescent usually is noted during lactation, but also can be due to trauma (including sexual, areolar hair pulling [leading to a Montgomery tubercle abscess], squeezing an acne lesion, piercing), duct abnormality (as duct ectasia), or reduced immune defenses due to chronic illness $(1,4,5,9)$. Mastitis develops to some degree in about $2 \%$ of pregnant women (lactational mastitis), usually in the postpartum period and less commonly, during pregnancy itself. Mastitis during lactation can be classified as an obstructive mastopathy, in which a major breast duct(s) becomes plugged leading to milk stasis, and secondary infection (due to Staphylococcus aureus [80\%-90\%], Streptococcus pyogenes, Micrococcus pyogencs, Escherichia coli, Pseudomonas aeruginosa, and others [as Mycobacterium tuberculosis]). Nipple trauma may also lead to infection. The same organism can be seen in the other, asymptomatic breast of the lactating female, as well as the pharynx of her infant. Milk from the infected breast may have an increased leukocyte count.

The infection usually develops with sudden onset of swelling, erythema, and tenderness; the skin is often warm to the touch in association with local cellulitis, regional lymphadenopathy, and if an abscess results, fluctuance develops. Extensive spread of the infection is usually limited by normal breast support tissue. including Cooper's ligaments; however, sometimes the support tissue can mask an abscess. Extensive breast tissue damage can result from large breast abscesses, usually developing in cases without proper management. The differential diagnosis of mastitis is listed in table 13. If mastitis does develop in an adolescent, pregnancy should be considered. Supportive laboratory studies include a needle aspiration with cultures, ultrasound, and possibly, blood cultures. 


\section{Table 13. Differential diagnosis of breast mastitis}

Lactational mastitis

Non-lactational mastitis

Mondor's disease

Mammary duct ectasia

Recurrent subareolar abscess

Trauma (sexual and non-sexual)

Breast malignancy

Management of mastitis in cases of milk stasis (with no associated infection) is by the use of warm compresses and continued breast feeding, as well as pumping out extra-produced milk, until normal balance is established between production and consumption. Antibiotics are used in cases of infection in order to cover the expected bacteria that are seen in such infections $(1,2,4,5,9)$. A variety of antibiotics have been used for 2 to 6 weeks, including amoxicillin, amoxicillin-clavulanic acid, erytbromycio, B-lactamase-stable penicillin [i.e., dicloxacillin], or a cephalosporin (i.e., cephradine or cephalexin); if fluctuance develops, incision and drainage of the abscess is necessary, using a circumareolar incision; the clinician should be suspicious of an abscess if antibiotics do not improve the initial infection (5,60). Antibiotics (sometime given intravenously) are continued until the infection is resolved, including resolution of the pain and cellulitis. If outpatient treatment with these antibiotics are not helpful, consider the possibility of an abscess and use metrooidazole or intravenous vancomycin (or other antibiotics) (61). Complications include recurrence (50\% in a breast abscess), breast necrosis or scarring [sometimes mistaken for a fibroadenoma], and in rare cases, septicemia. Breast feeding is continued unless purulent discharge develops. Ultrasonography can successfully help evaluate follow-up results.

\section{Non-lactational-nonpuerperal mastitis}

Non-puerperal mastitis is rare and its cause not known (see figures 30 and 31); its presentation is similar to that of lactational mastitis. There 
may be known precipitating factors, such as trauma (including sexual foreplay and nipple piercing), duct ectasia, epidermal cysts, local skin infections, cystic breast disease, abscess of the Montomery's glands or other sebaceous glands, syphilic chancre or gumma, tuberculosis, Wegener's granulomatosis, fungal infections, and protozoan infections.

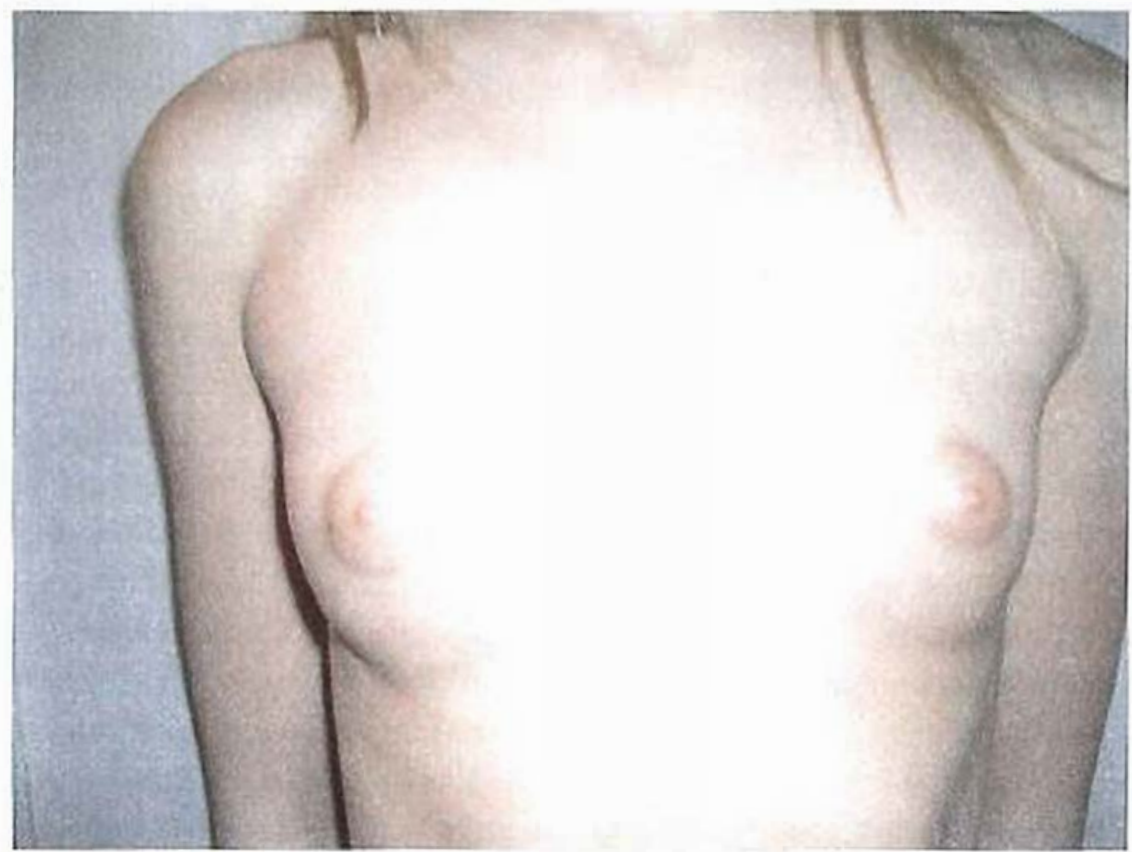

Figure 30. Mastitis, Right Breast in a 12 year old girl.

Management of bacterial mastitis, as already noted, includes warm compresses, antibiotic coverage, and sometimes, surgical drainage of the abscess. Table 13 reviews the differential diagnosis of mastitis, including Mondor' s disease, a usually benign condition characterized by superficial phlebitis in the breast skin; it typically develops after trauma (such as a biopsy or sports trauma), though sometimes the precipitating event is not identified. Mondor's disease presents with tender cords of inflamed veins that can be palpated, and usually resolves spontaneously, with or without mild analgesics (62). 


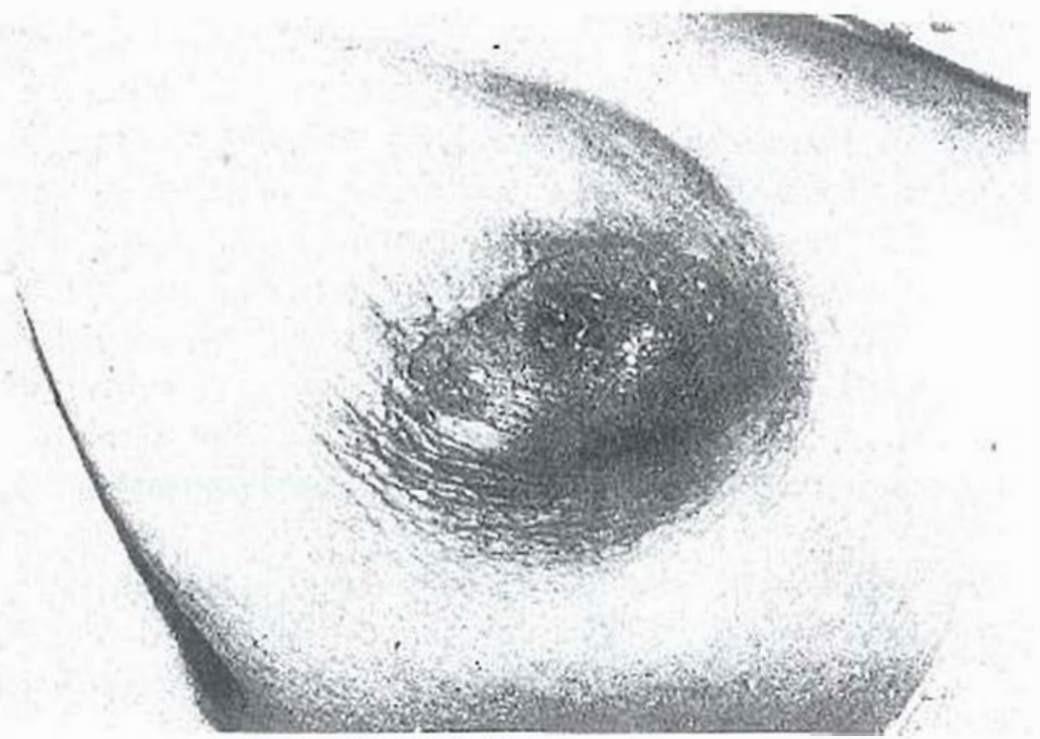

Figure 31. Staphylococcal Breast Abscess.

Body piercing in general has become more common in both female and male adolescents over the past decade. Cases of nipple piercing as the cause of local infection and disfiguration have been reported (4). Staphylococcus and Streptococcus species are the common causative organisms in these situations, but cases of Mycobacterium have also been noted. Treatment includes appropriate antibiotics and removal of the foreign body.

\section{SPORTS-INDUCED BREAST TRAUMA}

\section{Nipple trauma}

The nipple is a common site of injury, especially in female athletes, because it is the most prominent part of the breast $(1,2,63,64)$. Coarse clothing (such as tight-fining brassieres or shirts) can lead to an acute or chronic abrasive injury to the nipple, particularly during jogging or other actions, resulting in strong, repetitive nipple nibbing. It has been called jogger's nipple or bicyclist's nipple, the latter described in bicycle athletes who ride in cold wind and develop a raw, painful, bleeding 
nipple (s). Cold exposure or direct nipple stimulation affects local nipple muscle fibers, inducing an erect, prominent nipple. There is a 20: 1 ratio of males to females with nipple injury in long-distance runners. The differential diagnosis of such nipple disease includes sports-induced trauma, intraductal papilloma, and carcinoma. Sports-induced nipple injury is assessed with prevention of further nipple trauma and treatment of any secondary infection. Prevention of nipple injury during exercise or sports is listed in table 14 .

\section{Table 14. Prevention of sports-induced nipple injury*}
1. Use a plastic bandage (ie, a Band-Aid) or petroleum jelly (Vaseline) before and during the exercise
2. Use a properly fitted sports brassiere
3. Avoid exposure to cold temperatures
4. Use wind breaking material over the chest
5. Special attention during pregnancy, when nipples are more prominent

*Used with permission from: Greydanus DE, Patel DR.: The female athlete:

Before and beyond Puberty. Pediatr Clin North Am 2002;49:553-80.

\section{Breast trauma}

Though fortunately not a common occurrence, sports-induced trauma to the breasts can occur, leading to breast contusions, lacerations or hematomas $(63,64)$. Trauma often may occur during sports activity such as basketball or volleyball, but are noted in other sports a well. Contusions are due to superficial capillary rupture with ecchymosis along with edema, are usually mild, and may take up to three weeks to resolve. Abrasions result from various sports-related trauma, such as bicycle accidents (i.e., road racing, mountain biking), rodeo events, siding, or baseball (i.e., from sliding). Parts of the female's bra may induce injury because of bra clips, underwire metal hooks, clips or straps. Lacerations may occur as well. and proper closure is impor1.ant; observing for the development of a secondary abscess that can be painful is also part of the evaluation and follow-up. 
Hematomas can develop from a strong blow to the breast that causes bleeding from blood vessels deep in the breast tissue. Fat necrosis may later develop with secondary induration, scarring, and calcification lasting for many years and being confused with breast carcinoma. Fortunately, most breast hematomas resolve spontaneously, though some require surgical aspiration. Table 15 reviews basic management of these trauma-induced breast injulies. Sports-induced injuries can be reduced with the use of a properly fitting sports brassiere. This should be especially designed for athlete use and is made of cotton material; regular replacement is important, no later than every 6 months.

\section{Table 15. Management of trauma-induced breast injuries*}

\section{Contusion}

a. Application of cold (ice) every 15-20 minutes--several hours; do not apply ice directly to the skin but with a protective barrier.

b. Appropriate analgesia

c. Firm support

\section{Abrasion}

a. Direct pressure to control bleeding

b. Suturing may be necessary

\section{Laceration}
a. Close with steri-strips or sutures
b. Use good hygiene principles
c. Apply a firm post-closure dressing
d. Advice for the use of a supportive (sports) brassiere (including at night)
e. Pain and swelling can be reduced with a cold pack
f. Provide a tetanus toxoid if warranted
g. Antibiotics may be needed, depending on the situation

4. Hematoma

a. Most resolve without treatment

b. Surgical aspiration may be necessary

${ }^{\star}$ Used with permission from: Greydanus DE. Patel DR: The female athlete: Before and beyond puberty. Pediatr Clin North Am 2002;49:553-80. 


\section{BENIGN BREAST DISEASE}

Breast tissue is made up of epithelium, adipose tissue, and connective tissue. Breasts can normally be nodular during the childbearing years, with considerable cyclic volume changes. as much as $50 \%$ during a menstrual cycle. The adolescent is at the beginning of breast changes that will continue over several decades and there can be some confusion between normal changes on the one hand, and benign breast disease on the other $(1,2,9)$. Cyclic changes in the breast that reflect physiologic changes are normal and should not be labelled as a disease state. Thus, there can be a variety of changes, including physfologic (cyclic) swelling and tenderness (possibly part of PMT/ PMS), nodularity or significant lumpiness (cyclic or noncyclic), mastalgia (cyclic or noncyclic), and various dominant breast cysts or lesions $(1,2,9,14,22,65-71)$.

Benign single or multiple cysts are noted in adolescents, though not as commonly as a fibroadenoma is noted in adolescent females. These benign cysts arc typically not fixed to breast tissue and contain different amounts of sterile fluid that can be clear, brownish, or blood-tinged. Table 16 provides a partial classification of these benign cysts. A solitary large cyst (macrocyst or "blue-domed cyst") contains fluid with various colors (green, yellow, or black) that can be confused with a fibroadenoma or breast cancer; it is usually fluctuant, but can be hard or tense. Fine-needle aspiration (FNA) with cytology reveals the benign nature of the cyst and usually there is no recurrence $(68,69)$.

\section{Table 16. Types of benign breast cysts}

Fibrocystic change

Solitary large ("blue-domed") cysts

Simple single cyst

Galactoceles

Pseudolumps (normal physiologic changes)

Traumatic fat necrosis

Others

During lactation, galactocele(s) can develop from overdistention of lactiferous duct(s), usually presenting as a subareolar mass with a yellow 
discharge. The mass is excised if it does not disappear with continued lactation. Trauma to the breast can lead to the appearance of areas of fat necrosis in the breast.

A fine-needle aspiration of a cyst can be done testing for the presence of red blood cells (with a guaiac test) and abnormal cells (Papanicolaou fixative for cytology). If the mass disappears after aspiration, it is usually called a cyst and reexamination occurs in 2 to 3 months. If the mass reoccurs (as noted in as many as 50\%), ultrasound imaging can be obtained, as well as ultrasonically-guided aspiration with a pneumocystogram to evaluate the cyst walls (70). Air can be injected into the cyst wall to decrease the risk of cyst recurrence. If the aspiration is non-diagnostic or possible, an excisional (open) biopsy can then be done under local or general anesthesia, in order to obtain more information about the lesion. Figure 32 shows the ultrasound image of a benign breast cyst, figure 33 reveals the ultrasound image of a breast hemangioma, and figure 34 notes a "breast lesion" that was actually an axillary node.

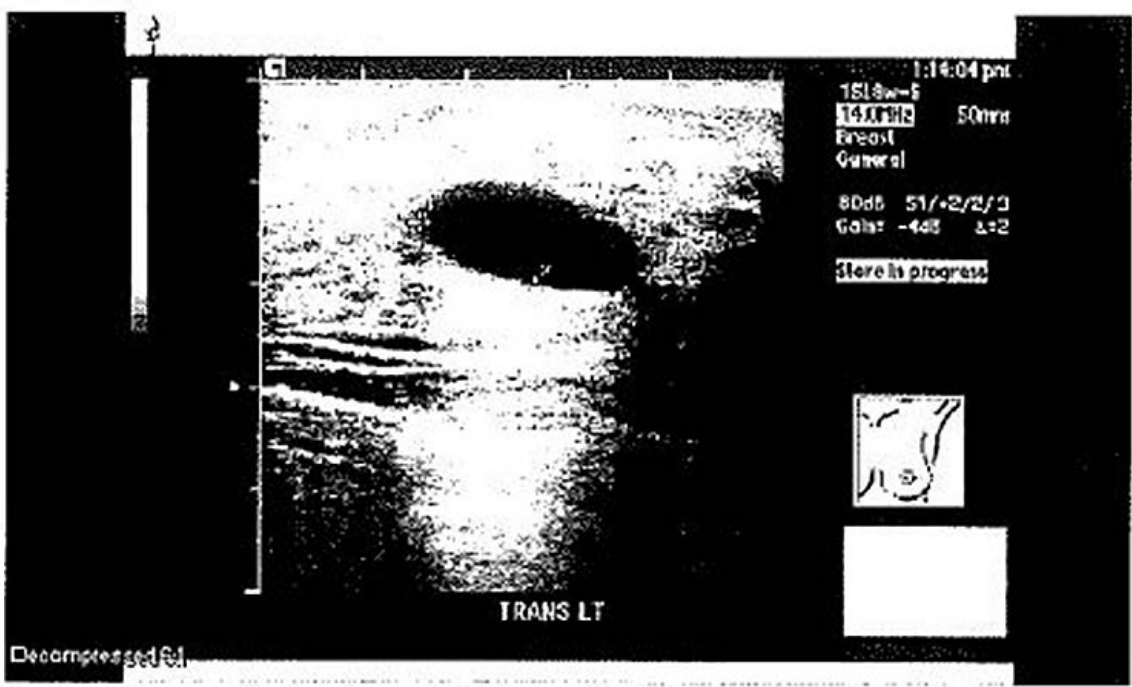

Used with permission from Kathleen Gadwood, MD, UltrasoundDivision, Radiology Department, Bronson Hospital, Kalamazoo, Michigan .

Figure 32. Ultrasound: Benign Breast Cyst. In the medial upper left breast. There is asimple $1.2 \times 0.7 \times 1.1 \mathrm{~cm}$ cyst. Scanning also reveals acyst at about 12:00 position in the left breast measuring $2.3 \times 0.9 \times 2.1 \mathrm{~cm}$. 


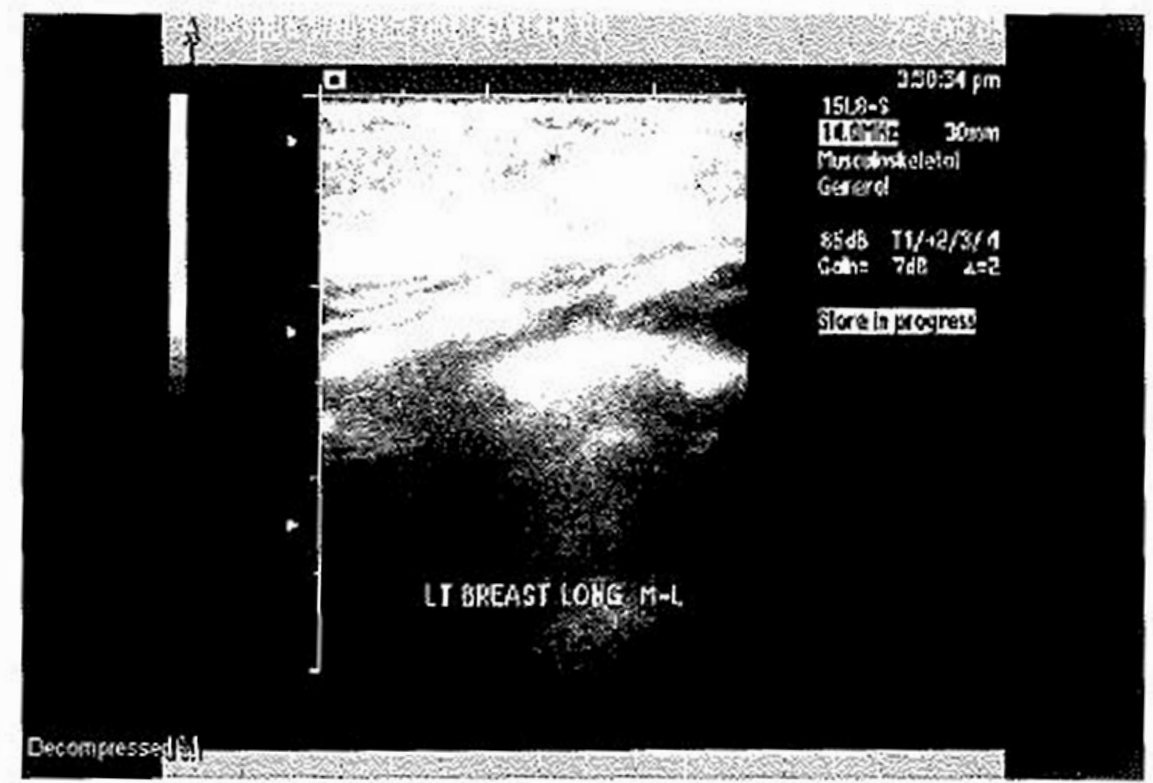

Used with permission from Kathleen Gadwood, MD, Ultrasound Division, Radiology Department, Bronson Hospital, Kalamazoo, Michigan.

Figure 33. Ultrasound: Left Breast. Mass, 3-month-öld. On Visual inspection, there is swelling of the tissues involving the left breast area. This feels soft on palpation. There is a bluish discoloration through the skin. Ultrasound scanning targeted here shows a hypoechoic mound-shaped area of tissue behind the areola, without discrete borders. Color Doppler readily demonstrates multiple blood vessels composing this mass. The vessels represent a combination of arteries and veins. The bulk of the soft tissue swelling seems to be caused by enlarged vessels. There are no other nonvascular spaces 10 suggest lymphatic tissue. This does not have the appearance of gynecomastia. Impression: Left breast mass is consistent with hemangioma or other vascular malformation. This does not look like a lymphangioma or soft tissue mass from a neoplasm.

\section{Fibrocystic change}

Formerly called fibrocystic disease, the term fibrocystic change is used to refer to hormonal-induced breast changes that are more physiologic in nature than overt disease. Though more common in females in their third decade of life and beyond, adolescent females may present with various degrees of breast tenderness and nodularity that 
tends to change over the course of the menstrual cycle. Diffuse cord-like thickenings and lumps may develop over time, while some patients present with vague lumps or nodules $(1,2,9,22)$. The second most common breast lesion in adolescents after the fibroadenoma is fibrocystic change (72). The etiology is unclear and often linked to estrogen and progesterone imbalances. Biopsy of these lesions reveals alveoli and terminal ducts with secretory material that are the basis of cystic development (57) (see figures 35-37). Some forms of benign breast disease (as cystic disease, atypical ductal or lobular hyperplasia, proliferative changes, others) are listed as risk factors for later breast cancer in the adult years $(4,17,72,73)$.

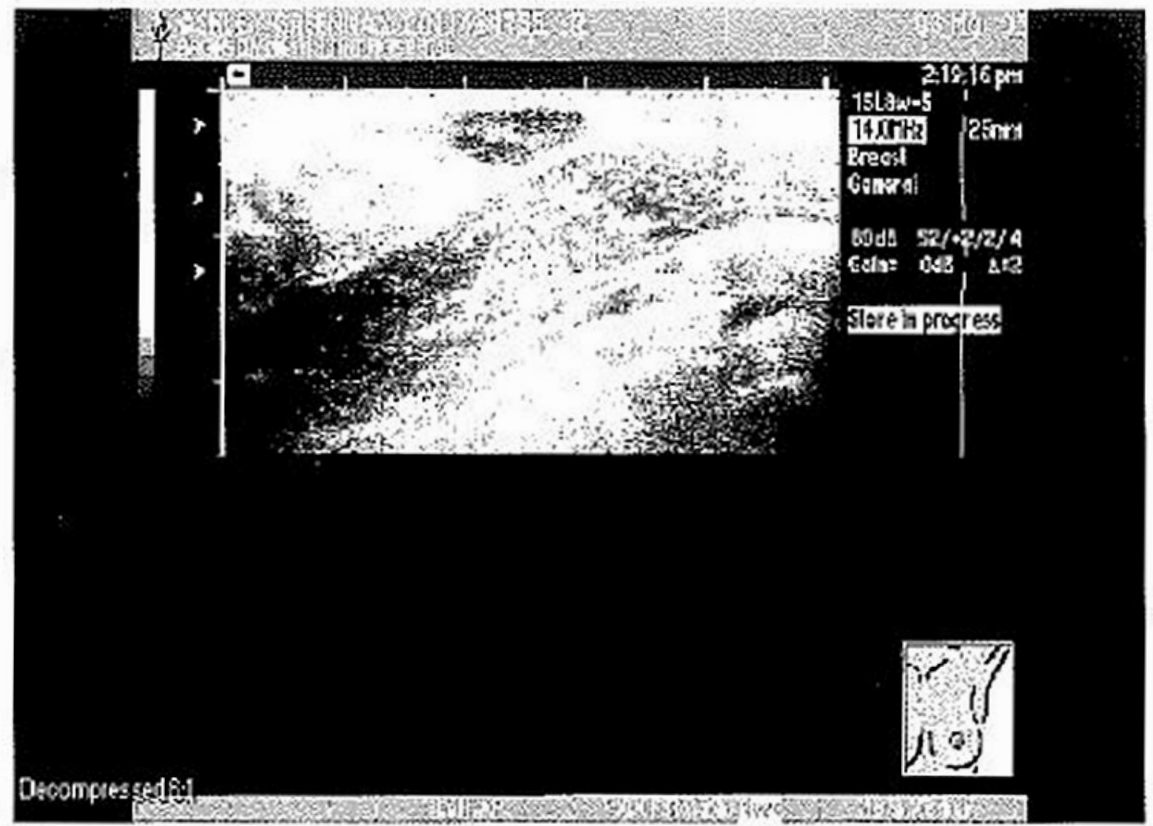

Used with permission from Kathleen Gadwood, MD, Ultrasound Division, Radiology Department, Bronson Hospital, Kalamazoo, Michigan.

Figure 34. Left Breast Lump. Scanning of tle left breast lump (upper outer aspect of breast) demonstrates a $1.2 \times 0.5 \times 1 \mathrm{~cm}$ lymph node. Vascular hilum noted. No other suspicious findings are noted. Impression: Approximately $12 \mathrm{x} 5$ $\mathrm{x} 11 \mathrm{~mm}$ lymph node that corresponds to the left breast palpable finding. 


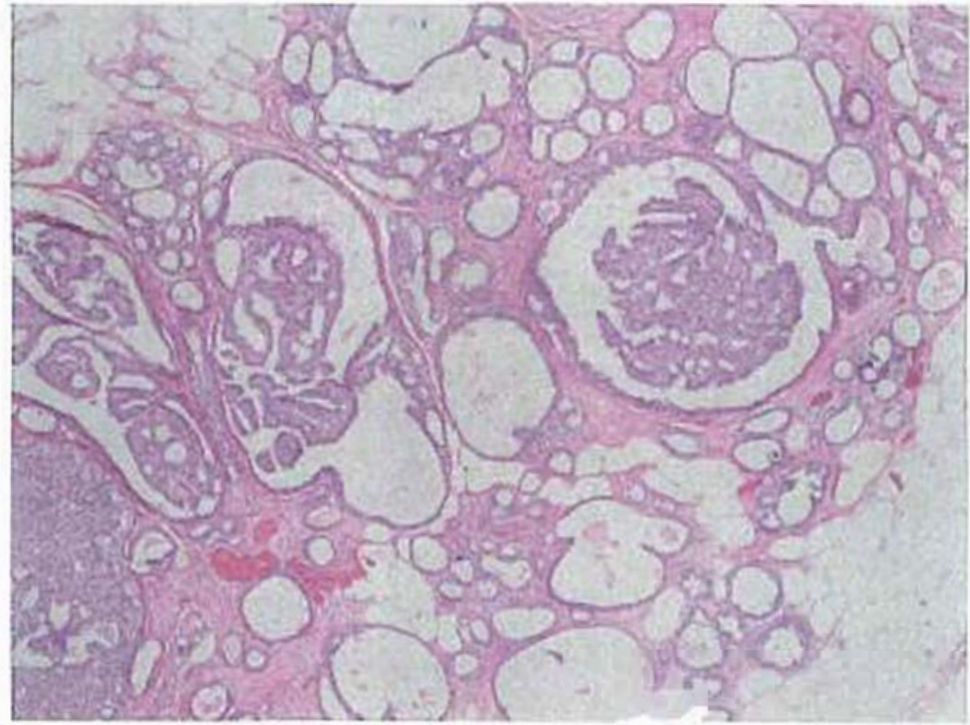

Used with permission from Jeffrey Pearson, MD. Medical Director, Pathology

Department, Bronson Hospital, Kalamazoo, Michigan.

Figure 35. Fibrocystic Change Histology.

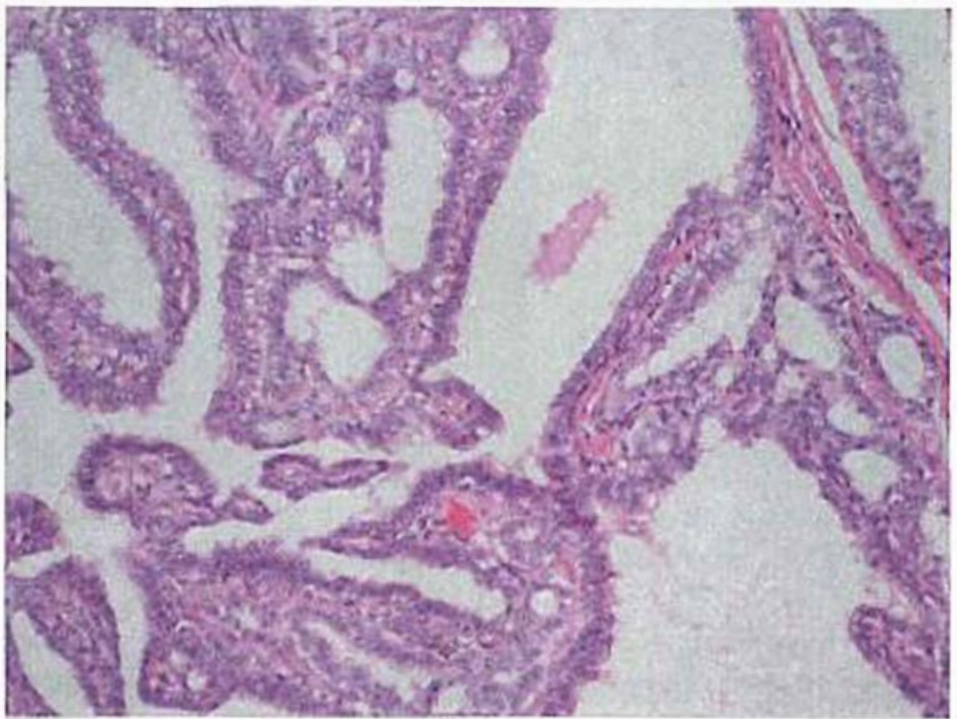

Used with permission from Jeffrey Pearson, MD, Medical Director, Pathology Department, Bronson Hospital, Kalamazoo, Michigan.

Figure 36. Fibrocystic Change Histology. 


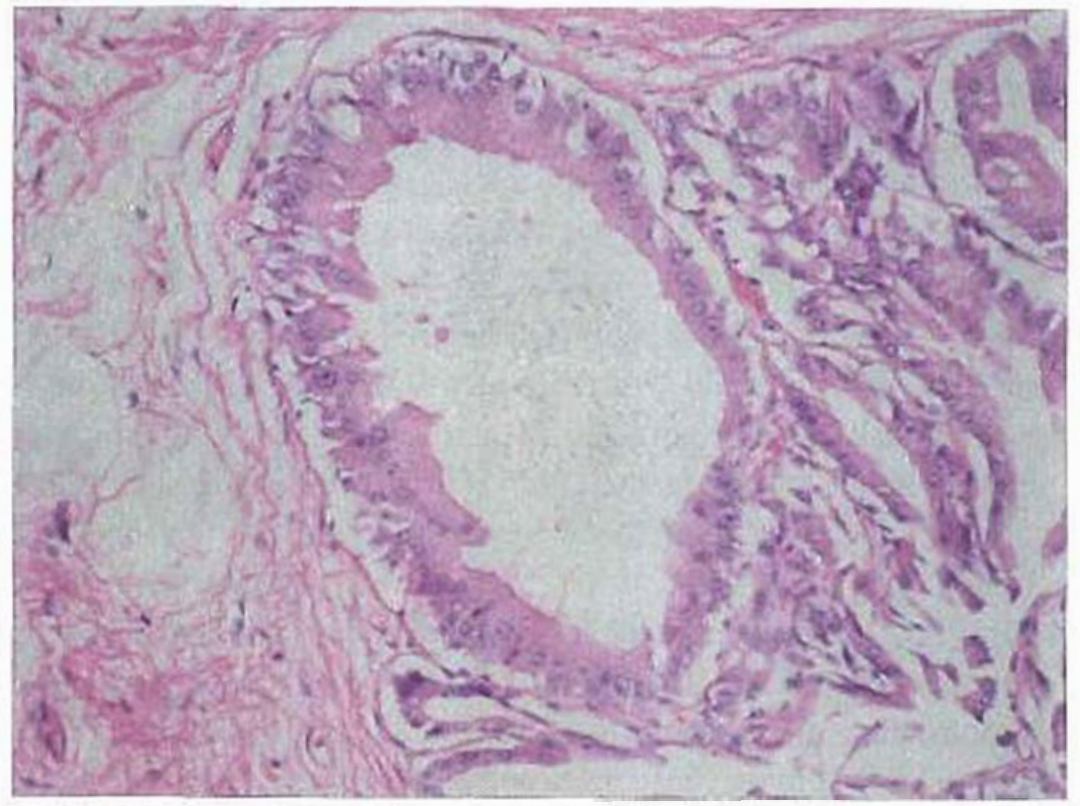

Used with permission from Jeffrey Pearson, MD. Medical Director, Pathology Department Bronson Hospital, Kalamazoo, Michigan.

Figure 37. Fibrocystic Change Histology.

Management depends on the severity of the condition and starts with reassurance of its benign nature, use of a well-fitting (sports) brassiere to prevent inflammation as well as stretching of breast ligaments, cold compresses, and a trial of mild analgesics (such as ibuprofen (other nonsteroidal anti-inflammatory drugs) or acetaminophen). In more severe conditions, oral contraceptives are beneficial in as many as $90 \%$ of patients, by reducing overt cystic breast production. Some medications have been used to manage fibrocystic change in adult women and include danazol, bromocriptine, and tamoxifen. These drugs have no proven value in adolescent females and introduce possible adverse effects, including teratogenicity and masculinization. Primrose oil may be beneficial at 3 to 4 grams per day (72). There is also no proven value for anecdotal management such as limiting methylxanthine (caffeine) ingestion or adding such substances as vitamin E or calcium (72). 


\section{Breast pain (mastodynia; mastalgia)}

Mastodynia often refers to breast pain that develops as part of physiologic swelling and nodularity of breast tissue occurring on a cyclic or non-cyclic basis $(1,2,4,9,14,22.57,74,75)$. It may develop or worsen 18 to 24 months after menarche and may, in some cases, he associated with episodes of breast hyperplasia (mammary dysplasia). Breast pain is observed in as many as $40 \%$ of reproductive age females and nearly $10 \%$ have their daily activity affected as a result (57). It may be part of a premenstmal tension syndrome (PMS), fibrocystic change, or related to such precipitants as pregnancy, infection. trauma, or medications (including oral contraceptives or other oral estrogen administration, phenothiazines, marijuana, others). Drugs that can lead to galactorrhea or gynecomastia can also cause breast pain (57). It is also irnportant to rule out other causes that may be confused with breast pain, such as chest wall pain (Tietze syndrome or osteochondritis), cervical spine disease, cardiac disease or others $(1,2,9,22)$. Thus, a careful assessment is necessary to identify the u11dcrlying cause of the pain.

Management of breast pain depends on its etiologic process (66). Mastalgia that seems to be related to menstrual cycle changes is usually mild and reassurance of its benign nature may be all that is necessary along with firm brassiere support and possibly. the use of mild analgesics. Underlying precipitating factors, such as marijuana or other drug use. should be eliminated. Oral contraceptives may improve (or worsen) breast pain and some females report anecdotal improvement with avoidance of methylxanthines (i.e., caffeine in cola, tea. coffee), chocolate. and dairy products.

The addition of evening primrose oil (y-linolenic acid) capsules (3 grams per day) is noted to help some females with cyclic mastalgia [61]. Vitamin E supplementation (600 IU per day of alpha-tocopherol) has anecdotal but no research-based support for improvement. Chasteberry is the fruit of the chasteberry tree that is found in western Asia, southwest Europe. and the southeastern United States. Chasteberry has been used for over many centuries for relief of various gynecologic symptoms and some authors note improvement in breast pain from taking chasteberry $(76,77)$. 
Some investigators have reported on the use of mastodinon for mild mastalgia and PMS (78). Danocrine is an anti-gonadotropin agent that is used by some clinicians to manage adult women with severe mastalgia; it has no proven benefit in adolescent females and its administration presents a number of potential severe adverse reactions, including teratogenicity, androgenization (with hirsutism), acne, weight gain, and others. Clinicians should always remember the classic dictum, primum non nocere (first, do no harm!).

\section{GyNECOMASTIA}

Visible or palpable mammary glaJld development in males is called gynecomastia, a term introduced by the famous physician, Galen, in the 2nd century $\mathrm{AD}(4,14,79-81)$. In the newborn male it is called neonatal breast hypertrophy, as reviewed earlier.' In prepubertal or pubertal gynecomastia, the subareolear enlargement is noticed starting at a diameter of $1 \frac{1 / 2}{2}$ or $2 \mathrm{~cm}$ and usually reaches $3 \mathrm{~cm}$, though much larger growth may occur; it can be unilateral, bilateral and/or familial. The tissue is usually firm, though it may blend into the surrounding tissue making differentiation from adipose tissue difficut Gyoecomastia is found in as many as two-thirds of males between Tanner Stage 2 and 4, usually beginning as a unilateral condition that eventually becomes bilateral. The breast swelling is often painful at presentation, and some youth complain of chest discomfort that may interfere with sports activity, including the development of nipple irritation (Jogger's Nipple) $(63,64)$. The etiology is usually postulated as an imbalance between estrogen and androgen along with issues involving end-organ response to hormonal changes. Histology reveals a pattern of connective tissue stroma with infrequent lactiferous duct tubules.

Most cases of gyuecomastia in young adolescent males are termed physiologic or idiopathic and resolve within 6 to 18 months (sometimes 2 years) (see figure 38). The evaluation should rule out pseudogynecomastia (i.e., appearance of breast enlargement that is really due to muscle development or obesity) and organic causes, as noted in table 17. Clinicians should he especially concerned about the development of breasts in males apart from Tanner stage 2 to 4 time period or if other 
problems are noted, such as history of estrogen ingestion, finding of small testicles, and others, as noted in table 18 (see figure 39). Breast manipulation may lead to galactorrhea. Breast cancer is very rare in males; however, there is an increased risk of breast cancer in those with Kleinfelter syndrome and those with a familial history of BRCA-2 mutations $(2,56)$. There is also an increased incidence of prostate cancer in those with a history of BRCA-1 mutation (see figure 40).

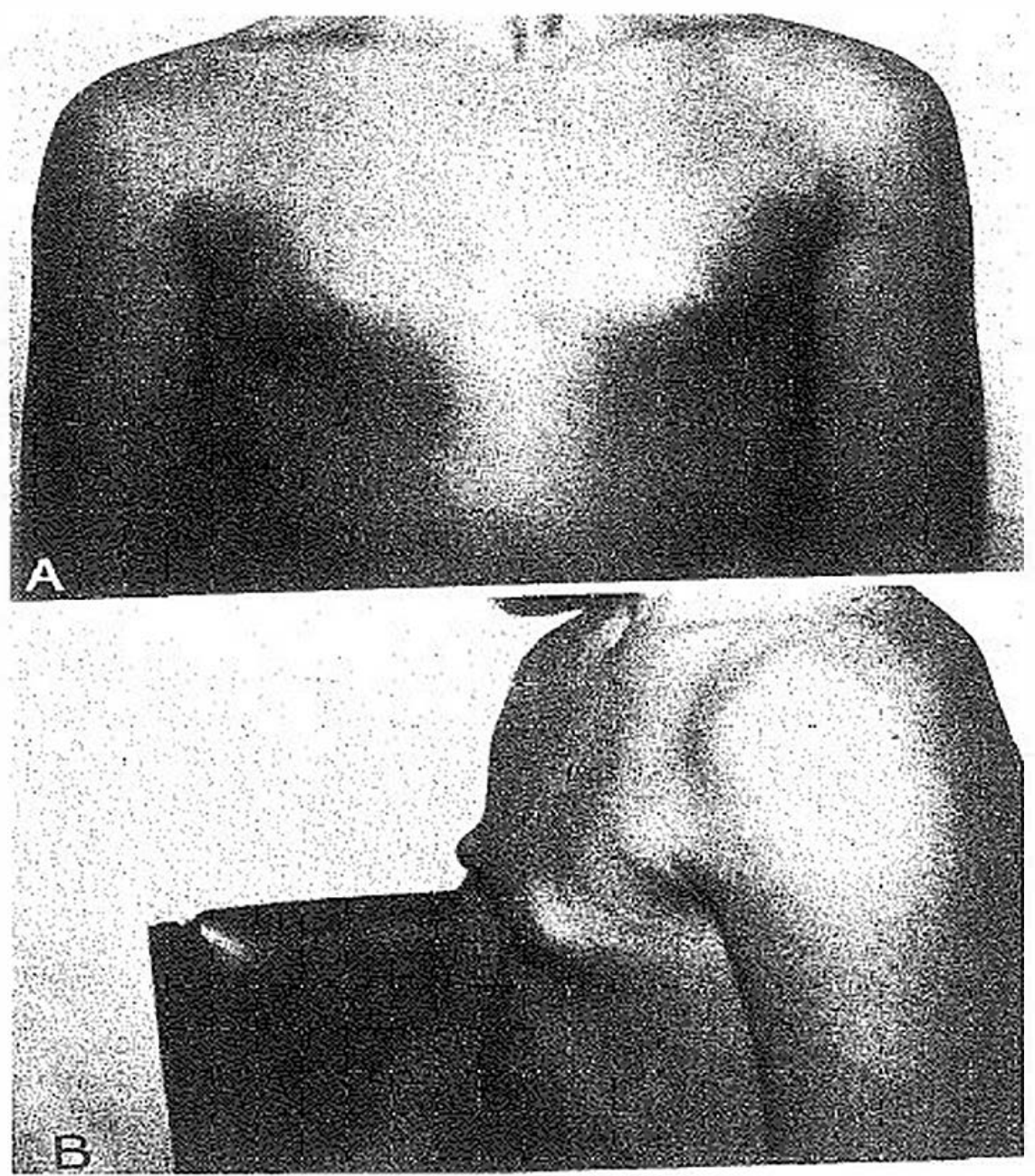

Figure 38. Gynecomastia in an Adolescent. B. Lateral View. 


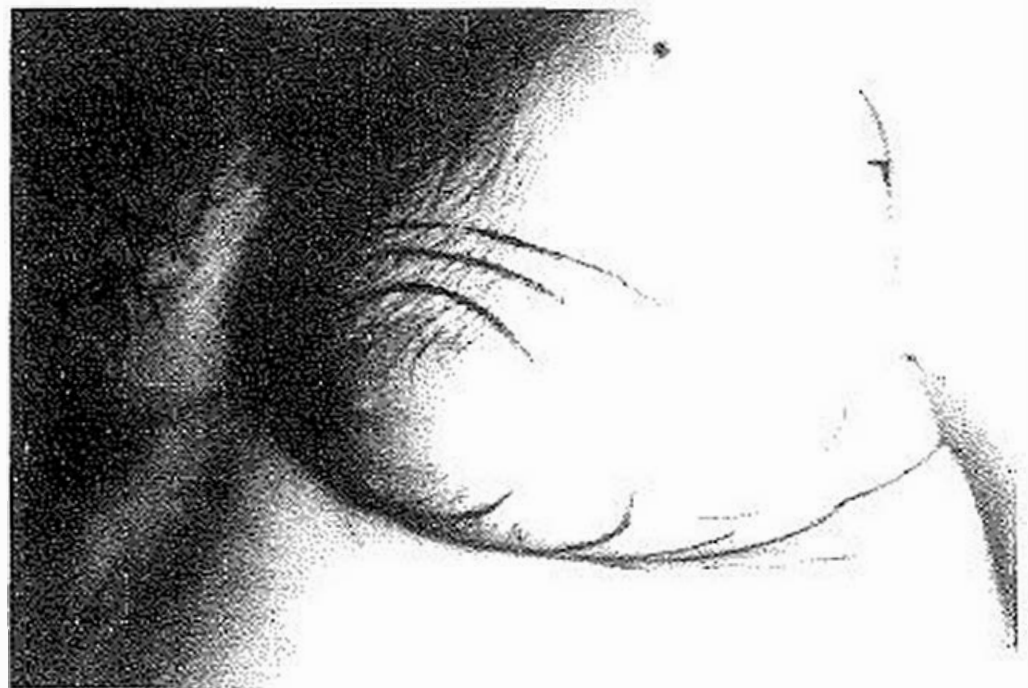

Figure 39. Gynecomastia in an Adult

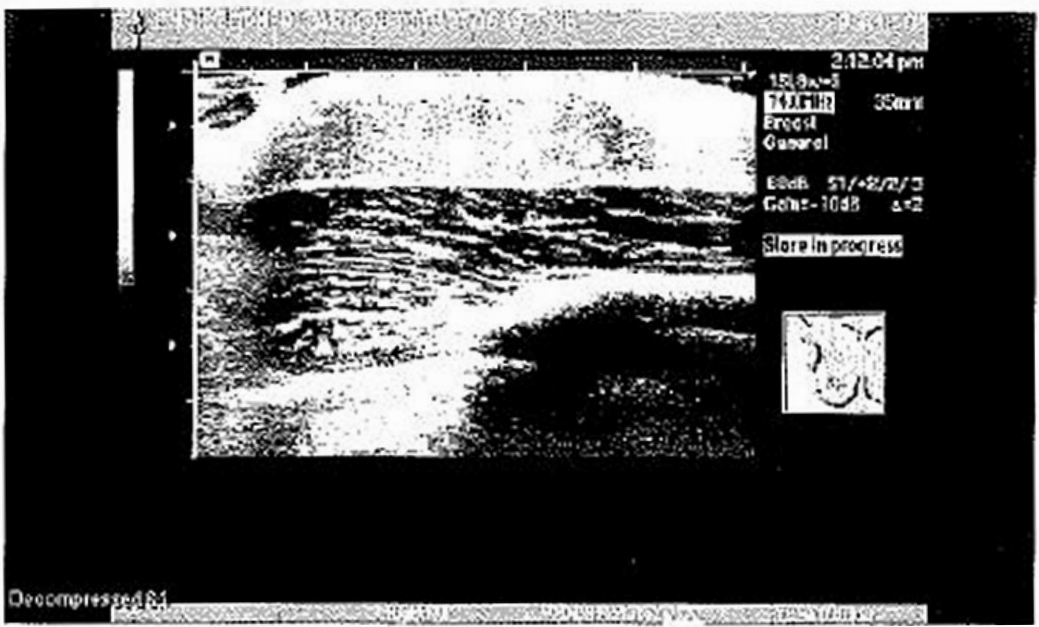

Used with permission from Kathleen Gadwood, MD, Ultrasound Division, Radiology Department, Bronson Hospital, Kalamazoo, Michigan.

figure 40. Breast Ultrasound. History of right nipple/subareolar enlargement, renal failure on dialysis, and hypertension in a 16 year old male. Ultrasound scanning shows an oval mound of uniform tissue in the right subarcolar area which measures 3.3 by 3.6 by $0.9 \mathrm{~cm}$. This seems to be: some focal glandulartissue. It is larger than on the left side, where the tissue measures 2.2 by 2.2 by $0.5 \mathrm{~cm}$. There is no abnormal mass, no cystic change. Impression: The palpable fullness on the right is consistent with gyoecomastia. 
Table 17. Causes of type II gynocomastia*

\begin{tabular}{|lc}
\hline Idiopathic & Miscellaneous drugs \\
Familial & Amphetamines \\
A ssociated with anosmia and & Anabolic steroids \\
testicular atrophy & Birth control pills \\
Reifenstein's syndrome & Busulfan (and other \\
Associatcd with hypogonadism and & demotherapeutic agents) \\
a small penis & \\
Others &
\end{tabular}

Klinefelter syndrome

Male pseudohermaphroditism

Androgen insensitivity syndrome

(Testicular feminization syndrome) Clomiphene

Tumors (seminoma, Leydig cell tumor, teratoma, feminizing adrenal tumor, hepatoma, bronchogenic carcinoma)

Cimetidine

Corticosteroids

Digicatis

Etretinate

Estrogens

Leukemia

Human chorionic

Hemophilia

gonadotropin

Leprosy

Thyroid dysfunction (hyper- and

hypothyroidism)

Cirrhosis of the liver

Traumatic paraplegia

Chronic glomerulonephlitis

Starvation (on refeeding)

Insulin

Isoniazid (and other

antituberculosis drugs)

Ketoconazole

Marijuana

Methadone

Reserpine

Spironolactone

Testosterone

Tricyclic antidepressants

Others

Used with permission from: Greydanus DE, Parks D, Farrell E. Disorders of the breasts in children and adolescents. Pediatr Clin North Am 1989;36(3):634. 


\section{Table 18. Evaluation of gynecomastia}

\section{History}

Timing of breast appearance

Family history

Systemic disease history

Weight changes

Use of drugs or medications

Physical Examination

Vital signs (height, weight, blood pressure)

Breast development (Tanner Stage and breast size)

Genitals (Tanner Stage and any abnormality of the genitals)

Neurologic examination.

Laboratory Studies (Serum)

\section{$\mathrm{LH}, \mathrm{FSH}$}

Testosterone (free. total)

Estradiol

SHBG (sex hormone hinding globulin)

HCG

17-urinary ketosteroids

DHBA-S

Androstenedione

Prolactin

Karyotype

Others

Management of idiopathic gynecomastia with breasts under $3 \mathrm{~cm}$ is usually reassurance that it is a "normal" occurrence, with further reassurance that he is not "feminine" or "turning into a female," and watchful waiting while the breast tissue resolves. If he is obese, measures for weight reduction may be helpful as well. Medications used for some adults with gynecomastia (i.e., antigonadotrophic agents [danazol], estrogen antagonists [clomiphene, tarnoxifen], or aromatase inhibitors [testolactone]) are. not recommended for adolescents since they have mo proven efficacy, have potentially serious side effects, and the breast development returns when the drug is stopped. Underlying disorders 
should be treated, as for example, testosterone replacement for a youth with small testes due to Kleinfelter Syndrome.

Large breasts (Tanner Stage 3 or 4 as well as over $4 \mathrm{~cm}$ ) are unlikely to fully resolve spontaneously. After two years of any size breasts, resolution is unusual because of the development of stromal fibrous tissue (57). Thus. the patient can be managed with surgery (i.e., periareolar incision and suction lipectomy or reduction mammoplasty) (4). Even males with small breasts may have severe emotional reactions to their breast development and should be offered surgery if necessary.

\section{NipPle disChaRge}

Nipple discharge can be caused by many factors and disorders, as listed in table 19; the basic categories of etiologies are idiopathic, druginduced, neurogenic, and endocrine/hormonal (including hypothalamic and pituitary disorders) $(1,2,4,9,14,22,57,82-84)$. The evaluation of nipple discharge looks at the nipple secretion (color and amount), history of trauma (including breast manipulation), breast disorders, or menstrual abnormalities. The physical examination in a female with nipple discharge involves a careful breast examination, including nipple palpation. A ductogram (galactography) may be helpful in identifying underling pathology, while surgery may be necessary to pinpoint the etiology of a breast lesion or remove an offending breast duct. Apocrine chromhidrosis refers to colored sweat secretion by periareolar apocrine glands.

\section{Table 19. Causes of nipple discharge}

1. Milky discharge
a Lactation
b. Breast cancer
c. Phenothiazine
d. Pituitary microadenoma
e. Elevated TSH (hypothyrnidism)
f Acromegaly 
2. Yellow discharge

a Galactocele

b. Physiologic effects

3. Serous, clear or greenish discharge: Physiologic Breast Cyst

4. Bloody discharge

a Cystic ductal hyperplasia

b. Intraductal papilloma

c. Cystosarcoma phyllodes

d. Papillary carcinoma

5. Brownish discharge

a Montgomery's gland secretion

b. Intraductal papilloma

6. Purulent discharge: mastitis or breast abscess

\section{GalaCtorRheA}

Galactorrhea refers to breast milk secretion apart from birth or abortion and the fluid may be white (milky), but also clear, green, or yellow. The discharge can be minimal or copious and a Sudan stain reveals the presence of fat globules in the discharge. Table 20 lists various causes of galactorrhea, though the most frequent factors are idiopathic (benign galactorrhea), suckling, self-manipulation, pharmacologic, pituitary prolactinoma, and hypothyroidism $(1,2,82)$. A pregnancy-related rise in prolactin levels can lead to a persistent state after a therapeutic abortion, delivery without nursing, or miscarriage. Idiopathic or benign galactorrhea refers to an end-organ hypersensitivity to normal prolactin levels. One cause of hyperprolactinemia is macroprolactinemia with elevated amounts of prolactin molecules that are larger than normal prolactin molecules, just as immunologically active, but not as biologically active; it represents a benign biochemical condition. 


\section{Table 20. Causes of galactorrhea*}

\section{Pregnancy, Lactation}

Stress. Exercise

Recent Pregnancy Terminated by Spontaneous or Induced Abortion

Neurogenic

Chest wall disorders

Bronchiectasis and chronic bronchitis

Herpes zoster

Chronic crutch use

Thoracotomy or thoracoptasty

Burns to chest wall

foreplay)

Breast (nipple) manipulation or stimulation (sexual

Chronic inflammatory disease or abscess of breast Psychogenic, includiug pseudocyesis and pseudonursiug Miscellaneous

Hysterectomy or uterine tumors

Laparotomy

Spinal cord disorders and surgery

Idiopathic normoprolaclinemia, with or without

amenorrhea

\section{Central nervous system abnormalities}

Diffuse brain disease

Coma

Pseudotumor cerebri

Encephalitis and sequelae

Uremia

Tumors, infiltrations, structural abnormalities

Neurocutaneous syndromes

Craniopharyngioma

Pineal tumors

Other intracranial tumors, cysts, and masses

Histiocytosis X

Sarcoidosis

Pituitary

Stalk section 


\section{Miscellaneous}

\section{Empty sella syndrome}

Pituitary infarction and Sheehan syndrome

Hyperprolactinemia with or without prolactinoma

Other functional pituitary tumors

Hypothyroidism and hyperthyroidism

Hypogonadism

Adrenal tumors and hypernephromas

Nelson syndrome

Testicular and ovarian tumors

Polycystic ovary syndrome (PCOS)

Starvation or refeeding (including anorexia nervosa)

Cushing disease

Chronic renal disease

Cirrhosis

Acute intermittent porphyria

Oral Contraceptive pills

Monoamine oxidase inhibitors

Amphetamines

Chlordiazepoxide

Meprobrunate

Metoclopramide

Bromocriptine withdrawal

Cimetidine and ranitidine

Tamoxifon

Verapamil

Isoniazid

Estrogens

Opiates (including codeine and heroin)

Phenothiazines, thioxanthenes, other psychotropic drugs

Tricyclic antidepressants

Other chemotherapy drugs (cisplatin, cytosine arabinoside, adriamycin)

\section{Others}

- With permission from: Greydanus DE Breast and gynecological isorders. In: Hofmann AD, Greydanus DE, eds. Adolescent medicine, $3^{\text {rd }}$ ed. Stamford, CT: Appleton Lange, 1997:531. 
A wide variety of pbarmacologic agents can induce byperprolactinemia due to underlying mechanisms as listed in table 21 . Hyperprolactinemia can develop in adolescent males who were treated in childhood with chemotherapeutic agents (as doxorubicin, cytosine arabinoside, cisplatin) or with testicular radiation. Other pharmacologic agents include oral contraceptives (noted with taking or withdrawal), methyltestosterone, spironolactone, reserpine, and others. The relationship of heavy marijuana use and galactorrhea remains anecdotal and controversial. If an offending drug is stopped, galactorrhea usually resolves. Hyperprolactinemia may result from hypothyroidism (rarely hyperthyroidism), stress, depression, anxiety, hypothalamic injury (surgery, rumor, infection), exercise, intercostal nerve stimulation, gonadal hypofunction, polycystic ovarian syndrome (PCOS) and other conditions noted in table 20. Moderate hyperprolactinemia (less than $1750 \mathrm{mU} / \mathrm{L}$ ) can develop in hypothyroidism and polycystic ovarian syndrome (PCOS).

\section{Table 21. Mechanisms of drug-induced galactorrhea}

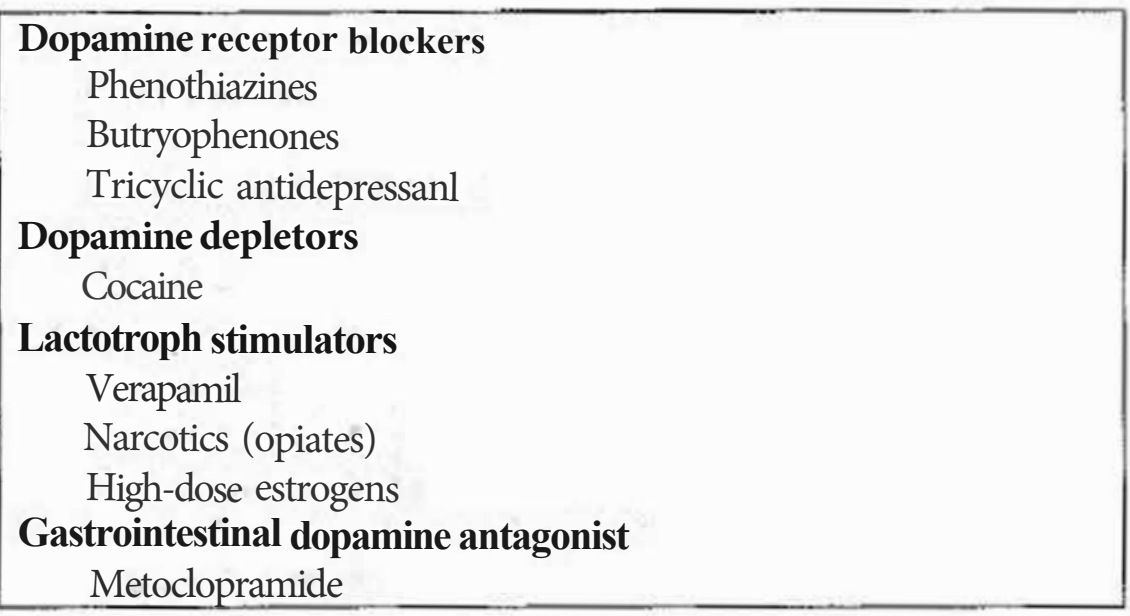

Evaluation of galactorrhea depends on the findings of a careful history and physical examination (1,2). A cytologic evaluation of the discharge fluid can be performed along with serum gonadotropins, prolactin, thyroid screen, and a bead MRI or CT. Management of galactorrhea depends on the underlying factor(s). If there is an offending 
drug, it should be stopped, as should breas1 manipulation if causative. Any thyroid dysfunction should be identified and corrected.

Most pituitary prolactinomas produce prolaclin levels of 80 to 200 $\mathrm{ng} / \mathrm{ml}$ or higher. The spectrum of this lesion ranges from a microadenoma (3-10 $\mathrm{mm}$ mass) to a macroadenoma (10 $\mathrm{mm}$ or more in diameter) with sella turcica erosion and optic nerve impingement. A microadenoma can present with a stable, non-progressive clinical course in which serum prolactin (less than $3000 \mathrm{mU} / \mathrm{L}$ ) is 2 to 10 times normal and symptoms include amenorrhea due to anovulation and galactorrhea. A macroadenoma may present with galactorrhea along with a variety of symptoms (see table 22); the prolactin level is very high at $8,000 \mathrm{mU} / \mathrm{L}$ or more. Visual field studies (looking for biteluporal hemianopsia) and a head CT/MRI may reveal the presence of a pituitary adenoma. Management of a pituitary adenoma depends on its size, but often a dopamine agonist is used, as bromocriptine, to remove the tumor if it is small enough; a macroadenoma may be reduced in size with a dopamine agonist followed by surgery (i.e., transspenoidal resection) [85]. Other dopamine agonists include L-dopa and ergotoxine.

\title{
Table 22. Symptoms of pituitary microadenoma
}

\author{
Menstrual change (Amenorrhea) \\ Headaches \\ Peripheral vision loss \\ Appetite changes \\ Abnormal sexual development \\ Polyuria, polyphagia, polydipsia \\ Infertility \\ Loss of libido \\ Impotence in males
}

\section{ACKNOWLEDGMENTS}

This chapter is a revised version and adapted with permission from Greydanus DE, Matytsina L, Gains M. Breast disorders in children and adolescents. Prim Care Clin Office Pract 2006: 33:455-502. 


\section{REFERENCES}

[1] Greydanus DE. Parks DS, Farrell BG. Breast disorders in children and adolescents. [Pediatr Clin North Amer] 19\&9;36:601-38.

[2] 2. Greydanus DE. Breast and gynecologic disorders. In: Hofmann AD, Greydanus DE, eds. Adolescent medicine. $3^{\text {rd }}$ ed. Norwalk. CT: Appleton Lange, 1997:520-34.

[3] Matytsina LA, Sergienko MY. Role of pediatric and adolescent gynaecologist in diagnostic and treatment of breast diseases in adolescent girls. [Bukovin's Med Bull] 2004;8(2):79-83.

[4] Arca MJ, Caniano DA. Breast disorders in the adolescent patient. [Adolesc Med]2004:15:473-85.

[5] De Silva NK, Brandt ML. Disorders of the breast in children and adolescents, Part 1: Disorders of growth and infections of the breast. [J Pediatr Adolesc Gynecol] 2006; 19(5):345-9.

[6] Simmons PS. Breast disorders in adolescent females. [Curr Opin Obstet Gynecol] 2001: 13:459-61.

[7] Templeman C. Breast disorders in the pediatric and adolescent patient. [Obstet Gynecol Clin North Am] 2000;27: 19-34.

[8] Breast concerns in the adolesceol. ACOG Committee Opinion No. 350. American College of Obstetricians and Gyaecologists. [Obstct Gynecol] 2006: 108: 1329-36.

[9] Greydanus DE, Matytsina LA, Gains M. Breast disorders in children and adolescents. [Prim Care Clin Off Pract] 2006;33(2):455-502.

[10] Garden AS. Sexual organ development. In: Garden AS, ed. Paediatric and adolesoentgynaecology. London: Arnold, 2001:3-14.

[11] Chard T, Lilford R Breast and lactation. In: Chard T, Lilford R. eds. Basic sciences for obstetrics and gynaecology. London: Springer. 1998: 103-4.

[12] Tanner J. Growth at adolescence. Oxford. Blackwell, 1962.

[13] Osborne MP. Breast anatomy and development In: Harris JR, Osborne CK. Morrow M, Lippman ME, eds. Diseases of the breast. Philadelphia, PA: Lippincott Williams Wilkins, 2000:1-13.

[14] Greydanus DE, Tsitsika AK. Gains MJ. The gynecology system and the adolescent. In: Greydanus DE, Feinberg AN. Patel DR, Homnick DN, eds. The pediatric diagnostic examination. New York: McGraw-Hill Med Publ, 2008:701,49.

[15] Matytsina LA. Hyperandrogenemia in girls: clinical indexes and correction. [Woman's Health] 2005;22(2):135,8.

[16] Chayka VK. Matytsina LA. Gynecological endocrinology of girls and adolescent girls. Donetsk: Lebed, 2004.

[17] Klein S. Evaluation of palpable breast masses. [Am Fam Phys] 2005; 71:17318. 
[18] Christensen AF, AI-Suliman N, Nielsen KR, et al. Ultrasound-guided drainage of breast abscesses: results in 151 patients. [Br J Radiol] 2005:78: 186-8.

[19] Chateil JF, Arboucalot F, Perel Y, et al. Breast metastases in adolescent girls: US findings. [Pediatr Radiol] 1998;28(11):832-5.

[20] Kronemer KA, Rhee K. Siegel MJ, et al. Gray scale sonography of breast masses in adolescent girls.[J Ultrasound Med] 2001 :20: 491-6.

[21] Garcia CJ. Espinoza A, Dinamarca V, et al. Breast US in children and adolescents. [Radiographies] 2000:20:1605-12.

[22] Santen RJ, Mansel R. Benign breast disorders. N Engl J Med 2005; 353:27585.

[23] Haagensen CD. Breasts. In: Rubin A, ed. Handbook of congenital malformation. Philadelphia, PA: WB Saunders, 1967: 15-8.

[24] Gendler LS. Joseph K-A. Breast cancer of an accessory nipple. N Engl J Med] 2005;353: 1835.

[25] Ferraro GA, Perrotta A. Rossano f, D'Andrea F: Poland syndrome: Description of an atypical valiant. [Aesthetic Plast Surg] 2005;29(1): 32-3.

[26] Kaplowitz PB. Puberty, normal and menarche. In: Hillard PJA, ed. The 5miuute obstetrics and gynecology consult. Philadelphia. PA: Wolters Kluwer/Lippincott Williams Wilkins, 2008:38-9.

[27] Biro F. Pubertal correlates in black and white girls. [J Pediatr] 2006: 148:23440.

[28] Kaplowitz PB. Pubertal development in girls: secular trends. [Curr Opin Obstet Gynecol] 2006; 18:487-91.

[29] Herman-Giddens ME, Harlan EA, Grillo GP. et al. Secondary sexual characteristics and menses in young girls seen in office practice: A study from the Pediatric Research in Office Settings Network. [Pediatrics] 1997:99:505.

[30] Draznin MB. Endocrine disorders In: Greydanus DE, Patel DR, Pratt HD, eds. Essential adolescent medicine. New York: McGraw-Hill Med Publ. 2006:299327.

[31] Norwitz BR, Arulkumaran S, Symonds J, Fowlie A. Paediatric and adolescent gynaecology. In: Norwitz BR, Arulkumaran S Symonds I, Fowlie A, eds. Oxford American handbook of obstetrics and gynaecology. New York: Oxforo Univ Press, 2007:479-83.

[32] McRath MH, Schooler WG. Elective plastic surgical procedures in adolescence. [Adolesc Med] 2004; J5:487-502.

[33] Rees TD, Aston SJ. The tuberous breast. Clin Plast Surg 1976; 3:339-45.

[34] Govrin YJ, et al, Familial juvenile hypertrophy of tle breast. [J Adolesc Health] 2004;35(2): 151-5.

[35] Wechselberger-Gottfried A. Juvenile gigantomastia treated by reduction mammoplasty. [Am J Surg] 2004;188(3):333-4.

[36] Sarwer DB, Brown GK, Evans DL. Cosmetic breast augmentation and suicide. [Am J Psychiatry] 2007:164(7): 1006-13. 
[37] Beach RK. Breast lump in adolescent girls. In: Berman S, ed. Pediatric decision-making, 4th ed.,Philadelphia. PA: Mosby, 2003:6.

[38] De Silva NK, Brandt ML. Disorders of the breast in children and adolescents, Part 2:breast masses. J Pediatr Adolesc Gynecol 2006; 19(6):415-8.

[39] Courtillot C. Plu-Bureau G. Binart N, et al: Benign breast diseases. [J Mammary Gland Biol Neoplasia] 2005:10(4):325-35.

[40] Greydanus DE, Tsitsika AK. Breast fibroadenoma and other benign breast masses. In: Hillard PJA, ed The 5-minute obstetrics and gynecology consult. Philadelphia, PA: Wolters Kluwer/Lippincott Williams Wilkins, 2008:76-7.

[41] Stone AM, Shenker-IR, McCarthy K. Adolescent breast masses. [Am J Surg] 1997;134:275-7.

[42] Hein K, Dell R. Cohen MI. Self-detection of a breast mass in adolescent females. J Adolesc Health Care 1982;3: 15-7.

[43] Tirvaki T, Senel E, Hucumenoglu S, et al. Breast fibroadenoma in female adolescents. [Saudi Med J]2007;28(1): 137-8.

[44] Marcopoulos C. Fibroadenoma of the breast: Is there any association with breast cancer? [Eur J Gynecol Oncol] 2004;25(4):495-7.

[45] Dhar A, Srivastava A. Role of centchroman in regression of mastalgia and fibroadenoma. World J Surg 2007;31(6): 1178-84.

[46] Fine RB. Percutaneous radiofrequency-assisted excision of fibroadenomas. [Am J Surg] 2006;192:545-7.

[47] Littrup PJ. Cryotherapy 'for breast fibroadenomas. Radiology 2005; 234: 63-72.

[48] Amerson JR. Cystosarcoma phyllodes in adolescent. females: A report of seven patients. [Am Surg] 1970;171:849-56.

[49] Agarwal P, Sparnon AL. Benigo breast lesions in adolesce.m girls: an overview with a case reporL [Pediatr Surg Intl 2005;21(5):381-2.

[50] Winchester DP. Breast cancer in young women. [Surg Clin North Am] 1996:76:279.

[51] Kalyani K, Sekhon MS. Bilateral breast cancer-under age 20. [J Adolesc Health] $2001 ; 28: 353$.

[52] Hindle WH, Pan EY. Breast disorders in female adolescents. [Adolesc Med] 1994;5(1): 123-9.

[53] Hindle WH, Sarkis N. Breast cancer and masses in women 22 years of age and younger. [Clin Obstet Gyneco]1 2002:45:758.

[54] Yaghan RJ, Bani-Hani KE. Male breast disorders in Jordan. Disease patterns and management problems. [Saudi MedJ] 2004:25:1877-83.

[55] Birnie A, Vanna S. Adenocarcinoma of the breast in a man. [N Engl J Med] 2005;353:286.

[56] Yager JD, Davidson NE. Estrogen carcinogenesis in breast cancer. [N Engl J Med] 2006:354:270-82.

[57] Kaul P, Beach RK. Breast disorders In: Greydanus DE, Patel DR, Pratt HD, eds. Essential adolescent medicine. New York: McGraw-Hill Med Publ. 2006:569-90. 
[58] Bhatia S, Robison LL, Oberlin O, et al. Breast cancer and other second neoplasms after childhood Hodgkin's disease.[N Engl J Med] 1996:334:74551.

[59] Kumar P, Clark M. Malignant diseases. In: Kumar P. Clark M, eds. Clirlical medicine. 6th ed. New York Elsevier/Saunders, 2005: 519-21.

[60] Lee MC Rios AM, Aten MF. et al. Management and outcome of children with skin and soft tissue abscesses caused by community-acquired methicillinresistant staphylococcus aureus. [Pediatr Infect Dis J] 2004;23(2):123-7.

[61] Shaughnessy EA. McLean K. Breast signs and symptoms: Breast mass. In: Hillard PJA.. ed. The 5-minuie obstetrics and gynecology consult. Philadelphia, PA: Wolters Kluwer/Lippincott Williams Wilkins. 2008:20-1.

[62] Cox EM, Siegel DM. Mondor disease: An unusual consideration in a young woman with a breast ma s. [J Adolesc Health] 1997;21:183.

[63] Greydanus DE, Patel DR. Baxter TL. The breast and sports: Issues for the clinician. [dolesc Med] 1998;9:533-50.

[64] Greydanus DB, Patel DR. The female athlete: Before and beyond puberty. [Pediatr Clin North Am) 2002;49:553-80.

[65] Brennan M, Houssami N, French J. Management of benign breast conditions. Pan :3-0ther breast problems. [Aust Fam Phys] 2005;34 (5):353-5.

[66] Morrow M The evaluation of common breast problems. [Am Fam Physician] 2000;61:2371-8.

[67] Marchant DJ. Benign breast disease. Obstet Gynecol Clin North Am 2002:29:1.

[68] Hindle WH. Lack of utility in clinical practice of cytologic examination of nonbloody cyst fluid from palpable breast cysts. [Am J Obstet Gynecol] 2000;182(6): 1300-5.

[69] Pacinda SJ. Fine needle aspiration of breast masses: a review of its role in diagnosis and management of adolescent patients. J Adolesc Health 1998;23;206.

[70] Weinstein SP. Spectrum of ultrasound findings in pediatric and adolescent patieors with palpable breast masses. [Radiographies] 2000;20:1613-21.

[71] Marchant DJ. Benign breast disease. Obstet Gynecol Clin North Am 2002;29:J.

[72] Lara-Torre E. Fibrocystic breast changes. In: Hillard PJA, ed. The 5-mioute obstetrics and gynecology consult. Philadelphia, PA: Wolters Kluwer/Lippincolt Williams Wilkins. 2008:106-7.

[73] Hartmann LC, Sellers TA. Fro.st MH, et al. Benign breast disease and the risk of breast cancer.[N Engl J Med] 200.5;353:229-37.

[74] Beach RK. Breast pain in adolescent girls. In: Bennan S, ed. Pediatric decision-making, 4th ed. Philadelphia, PA: Mosby, 2003:8.

[75] Olawaiye A. Mastalgia: A review of management. J Repro Med 2005;50:9339. 
[76] Richardson J. Breast signs and symptoms: Breast pain. In: Hillard PJA, ed. The 5-minute obstetrics and gynecology consult. Philadelphia, PA: Wolters Kluwer/Lippincott Williams Wilkins, 2008:22-3.

[77] Dennehy CE. The use of herbs and dietary supplements in gynecology: An evidence-based review. [J Midwifery Women's Health] 2006;51:402-9.

[78] Sergienko MY, Matytsina LA. Mastodinon in correction of disorders of reproductive system in adolescent girl/ [Woman's Reprod Health] 2005;21(1):141-4.

[79] Braunstein GD. Gynecomascia. N Engl J Med 1993;328:490.

[80] Lazala C, Saenger P. Pubertal gynecomastia. [J Pediatr Endocrinol Metab] 2002; 15:553-60.

[81] Templeman C. Hertweck SP. Breast disorders in the pediatric and adolescent patient. [Obstet Gynecol Clin North Am] 2000;27:19.

[82] Beach RK. Galactorrhea (nipple discharge) in adolescent girls. In: Berman S, ed. Pediatric decision-making, 4th. ed. Philadelphia, PA: Mosby, 2003:32.

[83] Arya AD. Pubertal gynocomastia In: Bhave SY, Nair MKC, Parthasarathy A, Menon PSN, Greydanus DE. Bhave 's textbook or adolescent medicine. New Delhi, India: Jaypee Brothers Med Publ, 2006:346-7.

[84] Parker WJ. Breast signs and symptoms: Breast discharge and galactorrhea. In: Hillard PJA, ed. The 5-minute obstetrics and gynecology consult. Philadelphia, PA: Wolters Kluwer/Lippincott Williams Wilkins, 2008:18-9.

[85] Schlechte JA. Prolactinoma: Clinical practice. [ N Engl J Med] 2003; 349:2035. 